\title{
New Methods for the Assessment of Flow Regime Alteration under Climate Change and Human Disturbance
}

\author{
Pengfei Shi ${ }^{1}$, Jiahong Liu ${ }^{2, *} \mathbb{0}$, Tao Yang ${ }^{1, *}$, Chong-Yu Xu ${ }^{3}$, Jie Feng ${ }^{4}$, Bin Yong ${ }^{1,5}$, Tong Cui ${ }^{6}$, \\ Zhenya $\mathrm{Li}^{1}$ and Shu $\mathrm{Li}^{7}$ (D) \\ 1 State Key Laboratory of Hydrology-Water Resources and Hydraulic Engineering, \\ Center for Global Change and Water Cycle, Hohai University, Nanjing 210098, China; \\ pfshi@hhu.edu.cn (P.S.); yongbin@hhu.edu.cn (B.Y.); 20190924@hhu.edu.cn (Z.L.) \\ 2 State Key Laboratory of Simulation and Regulation of Water Cycle in River Basin, \\ China Institute of Water Resources and Hydropower Research, Beijing 100038, China \\ 3 Department of Geosciences, University of Oslo, P.O. Box 1047, Blindern, 0316 Oslo, Norway; \\ c.y.xu@geo.uio.no \\ 4 China Institute of Water Resources and Hydropower Research, Beijing 100038, China; fengjie@iwhr.com \\ 5 School of Earth Sciences and Engineering, Hohai University, Nanjing 211100, China \\ 6 Department of Hydraulic Engineering, Tsinghua University, Beijing 100084, China; \\ cuitong@mail.tsinghua.edu.cn \\ 7 Yellow River Institute of Hydraulic Research, Yellow River Conservancy Commission, \\ Zhengzhou 450003, China; lididshu30@163.com \\ * Correspondence: liujh@iwhr.com (J.L.); tao.yang@hhu.edu.cn (T.Y.)
}

Received: 28 September 2019; Accepted: 15 November 2019; Published: 20 November 2019

\begin{abstract}
Climate change and anthropogenic activities do collectively lead to an alteration of the flow regime, posing a great influence upon the structure and persistence of native biotic communities within river ecosystems. The range of variability approach (RVA) method is commonly used to evaluate the flow regime alteration. However, it was reported to underestimate the degree of flow regime potentially. In this study, two new assessment methods/metrics for evaluating the process behaviors of the flow regime are developed based on Euclidean distance and dynamic time warping (DTW) distance. They are then integrated with the metric of RVA, generating two composite metrics that represent both frequency and process changes of the flow regime. The new methods/metrics were applied to identify the flow regime alteration in a typical basin in the middle reaches of the Yellow River, China. The results show that the composite metrics consistently reveal a high alteration degree of flow regime in the basin. The decreased biological integrity of fish demonstrates the reasonability of the high-level overall alteration to some degree. The updated methods enable more scientific evaluation for the complex hydrologic alteration under a changing environment.
\end{abstract}

Keywords: alteration of flow regime; range of variability approach (RVA); indicators of hydrologic alteration (IHAs); updated assessment methods; the middle reaches of the Yellow River Basin; changing environment

\section{Introduction}

The integrity and biodiversity of riverine ecosystems are related to natural flow regime [1-3]. Alteration of the flow regime would arouse the emergence of some ecological problems, such as failed recruitment, local extinction and the success invasion of exotic species $[4,5]$.

It is one of the global issues, especially under the changing environment, which has attracted increasing concern from scientists and governments [6,7]. Hydrological alteration and its impacts on 
ecosystems play a vital role for the sustainable development of water resources [8,9], and changes of different hydrological variables result in complex set impacts [10-13]. Assessment of flow regime alteration is therefore a basic step calling for appropriate indicators. Many types of flow metrics and statistical methods have been proposed to analyze the impact of changes in flow regimes [14-17]. Indicators of hydrologic alteration (IHAs) are among the most popular metrics being widely used. IHAs were developed based on 32 parameters in five groups (i.e., flow magnitude, timing, duration, frequency and change rate) [18]. The IHAs are reported to be representative enough to describe the statistical alteration in the complete set of hydrologic indices [19]. The range of variability approach (RVA) was proposed to measure hydrologic changes, suggesting that the 25th and 75th percentiles of the IHA metrics should be the targets for maintaining environmental flow $[10,20,21]$.

Notwithstanding, shortcomings exist in the current method to some extent. In the RVA method, the difference between the proportions (frequencies) of pre-impact and post-impact values falling within the target range is considered to represent the degree of alteration [20]. If the frequency is the same for pre-impact and post-impact time series, the flow regime alteration is considered to be negligible [22]. Only frequency is considered, resulting in that the RVA may underestimate the alteration of the flow regime. It was reported that the RVA could not account for alterations of the order of hydrologic year types [22]. For instance, the wet, average and dry years occur once every three years under a natural flow regime during a 30-year period, if the occurrence order changes but the frequency does not (e.g., all of the wet years occur in the first 10 years, and the average and dry years happen in the second and the last 10 years, respectively), the flow regime alteration is 0 according to the RVA method. Obviously, it does not reveal the true alteration.

Yin et al. [22] therefore developed a new method to assess the flow regime alteration by considering the order of hydrologic year types (HYTs), providing beneficial insight to conduct a more reasonable assessment of flow regime alteration. Nevertheless, taking the HYTs into consideration could not reflect the temporal changing behaviors for each IHA, which are actually important for the ecosystem. For example, low flow occurring in a certain period will bring a more destructive effect on aquatic species compared with that it occurs evenly. Hence, an updated assessment method considering the process changes of indicators is called for to precisely evaluate flow regime alteration. Actually, an important feature representing the difference between two sequential data is the similarity/diversity. The concept of similarity and its dual concept of diversity play a fundamental role in several Quantitative Structure-Activity Relationship (QSAR) strategies, chemometrics and library searching methods, virtual screening, as well as in relatively new fields such as genomics and proteomics [23]. It can be employed as a measure to characterize the changing behaviors of these IHAs. However, less attention has been paid to understanding the flow regime alteration by using the similarity/diversity of time series. Hence, we try to evaluate the alteration of the flow regime by using this similarity/diversity measure.

As the second longest river in China, the Yellow River plays a crucial role in facilitating the social-economic development and maintaining ecosystem health in north China. The discharge of the Yellow River has significantly decreased due to climate change and intensifying human activities [24-26]. $\mathrm{Li}$ et al. [27] studied annual streamflow and sediment discharge at a tributary in the middle reaches of the Yellow River, and reported a significant downward trend. Yang et al. [28] revealed that the dam construction triggers a middle level of hydrologic alteration, and climate change makes the situation more complicated. Though numerous studies reported the changes of flow regime in the middle reaches of Yellow River [25,28-31], a systematic assessment on this flow regime alteration, considering both the frequency changes and process changes, is limited so far. Climate change together with human activities undoubtedly makes the flow regime more complicated in terms of both the statistical characteristics and the temporal changing behaviors [28,32,33]. Consequently, a comprehensive assessment on flow regime alteration is urgently needed for the middle reaches of the Yellow River.

Recognizing the above concerns, this study aims to: (1) Characterize the changes in flow regimes by using IHAs, (2) develop updated assessment methods for flow regime alteration by using the 
similarity/diversity measure, which is then incorporated with the RVA method to construct composite assessment metrics, (3) identify the flow regime alteration in a typical basin in the middle reaches of the Yellow River Basin, China, and compare the results by different methods, and (4) explore the possible implications of hydrological alteration on the ecosystem to develop knowledge for sustainable water resources and eco-environmental management.

\section{Study Area, Data, and Methodology}

\subsection{Study Area}

The Yellow River Basin has served as the "cradle of Chinese civilization" over the past millennia and continues to play a critical role in the development of China [30,34]. The middle reaches of the Yellow River (MRYR) flow through the Loess Plateau. The water from MRYR accounts for $44.3 \%$ of the Yellow River streamflow, and the sediment accounts for $88.2 \%$ of the Yellow River sediment. The MRYR, with an area of $344,000 \mathrm{~km}^{2}$, is located between the longitudes $104^{\circ} \mathrm{E}-113^{\circ} \mathrm{E}$ and latitudes $32^{\circ} \mathrm{N}-42^{\circ} \mathrm{N}$. The Wei River is the largest tributary of the Yellow River, which is located at the MRYR [35]. The Wei River Basin includes Wei River, Jinghe River, and Beiluo River. The Jinghe River Basin $\left(45,421 \mathrm{~km}^{2}\right)$ is selected as the study area of this work. It is located between latitudes $34^{\circ} 46^{\prime} \mathrm{N}-37^{\circ} 19^{\prime} \mathrm{N}$ and longitudes $106^{\circ} 14^{\prime} \mathrm{E}-108^{\circ} 42^{\prime} \mathrm{E}$, whose outlet is the Zhangjiashan Hydrological Station (Figure 1). The elevation of this Jinghe Basin ranges from 421 to $2922 \mathrm{~m}$ a.s.l. The area is characterized by a temperate, continental climate. Mean annual temperature is $8{ }^{\circ} \mathrm{C}$ and the mean annual precipitation is around 350-600 mm, which mainly concentrates in summer and autumn (fall) (July to September). A series of floods happen during the rainy season. The average annual streamflow is about $18.32 \times 10^{8} \mathrm{~m}^{3}, 70 \%$ of which concentrates from June to October.

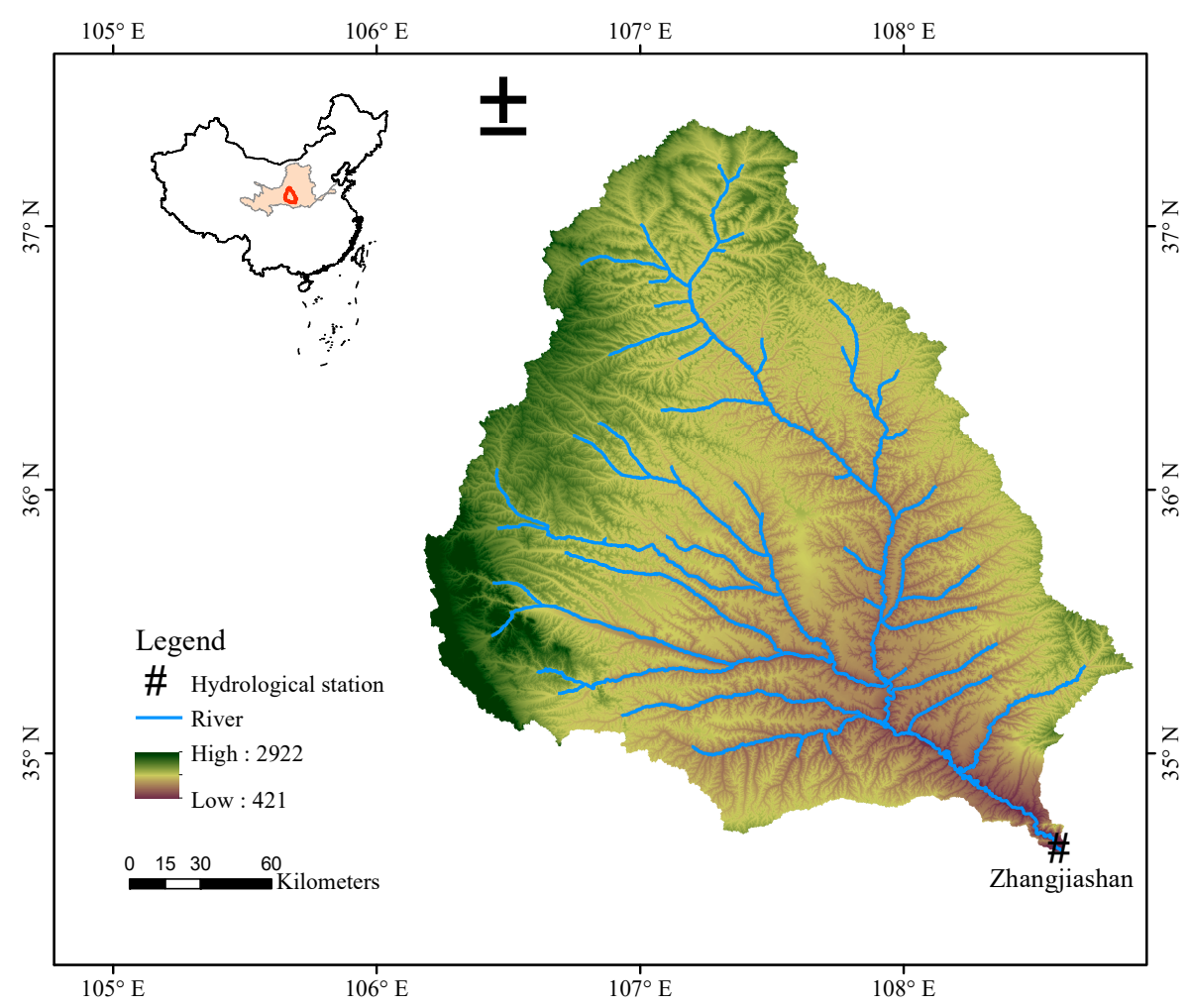

Figure 1. Map of China and the location of the Jinghe Basin in the middle reach of the Yellow River Basin.

\subsection{Data}

Daily discharge at the Zhangjiashan Station (1956-2010) is collected from the local hydrological bureau. The discharge data is measured by using the velocity-area method. The velocity is measured 
by a hydrometric propeller, and the area is calculated using the river width and the depth of river measured by sounding rod. The discharge is monitored twice every day in the normal season and several times (about once per hour) in the flood season. Daily discharge is the mean value of the monitoring data within one day. The homogeneity and reliability of the data were checked and firmly controlled by the hydrological bureau before the data were released. It is reported that the variation of annual runoff depth in the Jinghe Basin is $-1.0--0.5 \mathrm{~mm} /$ year [31], indicating an obvious downward trend of streamflow and water resources. In addition, poor biological integrity was reported over the basin in these years $[36,37]$.

\subsection{Methodology}

The framework of this study is presented in Figure 2. The Mann-Kendall statistical test is employed to detect the change point of streamflow series. The streamflow series (1956-2010) is therefore divided into the pre-impact period and post-impact period by the abrupt point. The flow regimes are characterized by indicators of hydrologic alteration (IHAs) that are calculated based on the pre-impact and post-impact streamflow data. The commonly used range of variability approach (RVA) method is used to detect the alteration of flow regimes (denoted by $D_{m}$ value). Then two new assessment methods are developed based on the concept of similarity/diversity. One is developed based on dynamic time warping (DTW) distance (denoted by $S D_{m}$ value) and the other one is based on Euclidean distance (denoted by $S_{m}$ value). These three methods describe the alteration degree in terms of the prospective of frequency changes as well as process changes. In addition, the individual metrics are integrated pairwise to obtain two composite metrics $\left(O D_{-} S D_{m}, O D_{-} S_{m}\right)$ for comprehensive description of the alteration degree of flow regimes. The overall alteration degree for 32 IHAs by the five metrics $\left(D_{m}, S D_{m}, S_{m}, O D_{-} S D_{m}, O D_{-} S_{m}\right)$ are denoted as $D, S D, S, O D \_S D$ and $O D \_S$, respectively. In addition, the alteration degrees calculated by these five metrics are compared. Some terminology and the description in this work are shown in Table A1.

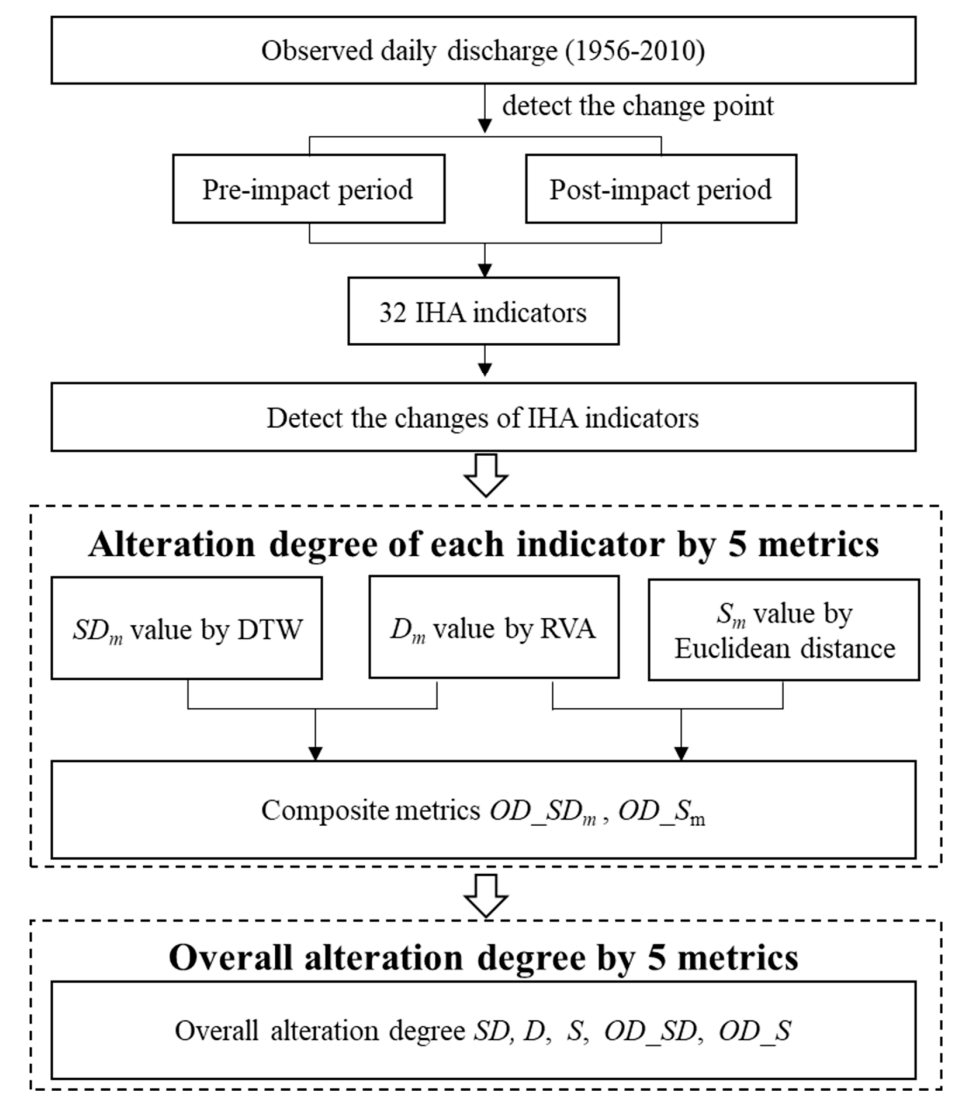

Figure 2. Overall procedures for assessing flow regime alteration. 


\subsubsection{Mann-Kendall Statistical Test}

Mann-Kendall [38] and Pettitt's change point [39] are commonly used to detect the change point of the streamflow series.In this work, the Mann-Kendall (M-K) test $[40,41]$ is employed to analyze trends and to detect abrupt changes in the time series of the streamflow. The M-K method defines a test statistic, $d_{k}$, that is calculated based on the rank series, $r_{i}$ as in the following Equation:

$$
d_{k}=\sum_{i=1}^{k} r_{i}(2 \leq k \leq n)
$$

where, $r_{i}$ is defined as:

$$
r_{i}=\left\{\begin{array}{cc}
+1 & \text { if } x_{i}>x_{j} \\
0 & \text { others }
\end{array}(j=1,2, \ldots, i)\right.
$$

where, $x_{i}$ refers to the time series, $d_{k}$ refers to the sum of $r_{i}$ related to $x_{i}$. The definition of the statistic index, $U F_{k}$, is then calculated as

$$
U F_{k}=\frac{d_{k}-E\left[d_{k}\right]}{\sqrt{\operatorname{Var}\left[d_{k}\right]}}
$$

where $E\left[d_{k}\right]=n(n-1) / 4$ is the expected value of $d_{k}$, and $\operatorname{Var}\left[d_{k}\right]=n(n-1)(2 n+5) / 72$ is the variance of $d_{k}, n$ is the number of time series data, and UF follows the standard normal distribution. In a two-sided test for trend, if $|U F|>U_{1-\alpha / 2}$, then the null hypothesis is rejected at the significance level of $\alpha$, where $U_{1-\alpha / 2}$ is the critical value of the standard normal distribution. A corresponding rank series is then obtained by arranging the time series in reverse order, and the same processes are conducted to obtain the other statistical index, $U B$. A positive value of $U F$ indicates an upward trend, and a negative value denotes a downward trend [42,43]. In this study, $\alpha$ equals to 0.05 and the corresponding $U_{1-\alpha / 2}$ equals to 1.96. If $U F>1.96$ or $U F<-1.96$ in a time series, then it shows a significant increasing or decreasing trend at the level of 0.05 . Additionally, if the two lines, $U F$ and $U B$, have an intersection point within the significance level, the intersection point is regarded as an abrupt point in the time series with a significance value of $\alpha$.

\subsubsection{The IHA Method for Hydrologic Alteration Assessment}

The IHA method [18] is based on a set of 32 indicators classified into five groups, including magnitude, duration, timing, frequency and change rate (Table 1). The magnitude of the water condition at any given time is a measure of the availability or suitability of the habitat. The timing of the occurrence of particular water conditions can determine whether certain life-cycle requirements are met, or can influence the degree of stress or mortality associated with extreme water conditions, such as floods or droughts. The frequency of occurrence of specific water conditions such as droughts or floods may be tied to reproduction or mortality events for various species, thereby influencing population dynamics. The duration of time over which a specific water condition exists may determine whether a particular life-cycle phase can be completed, or the degree to which stressful effects such as inundation or desiccation can accumulate. The rate of change in water conditions may be tied to the stranding of certain organisms along the water's edge or in ponded depressions, or the ability of plant roots to maintain contact with phreatic water supplies. For more details, refer to Richter et al. [18]. The indicators are calculated based on daily discharge data. The IHA is generally calculated following the steps below:

(1) Divide the daily discharge data into two parts, i.e., a baseline pre-impact period (here from 1959-1996) and a perturbed post-impact period (here from 1997-2010).

(2) Calculate the median and interquartile range of the magnitude and variability of each IHA, respectively.

(3) Count the number of indicators falling within its target range and identify the alteration degrees of the flow regime. 
Table 1. The 32 indicators of hydrologic alteration (IHAs) [10,18,44].

\begin{tabular}{|c|c|c|}
\hline IHA Parameters Group & Hydrologic Parameters & Examples of Ecosystem Influences \\
\hline 1. Magnitude of monthly water conditions & Mean discharge for each calendar month (12 parameters) $\left(\mathrm{m}^{3} / \mathrm{s}\right)$ & $\begin{array}{c}\text { Provide availability of habitat, soil moisture, water and food; access by } \\
\text { predators to nesting sites; } \\
\text { functional link to water temperature, oxygen levels, photosynthesis }\end{array}$ \\
\hline \multirow{3}{*}{$\begin{array}{l}\text { 2. Magnitude of annual extreme discharge events with } \\
\text { different durations }\end{array}$} & Annual 1-,3-,7-,30-,90-day minimum flow $\left(\mathrm{m}^{3} / \mathrm{s}\right)$ & \multirow{3}{*}{$\begin{array}{l}\text { Creation of sites for plant colonization; structuring of river channel morphology } \\
\text { and physical habitat conditions; nutrient exchanges between rivers and } \\
\text { floodplains; distribution of plant communities in lakes, ponds and floodplains }\end{array}$} \\
\hline & Annual 1-,3-,7-,30-,90-day maximum flow $\left(\mathrm{m}^{3} / \mathrm{s}\right)$ & \\
\hline & Base-flow index $\left(\mathrm{m}^{3} / \mathrm{s}\right)$ & \\
\hline \multirow{2}{*}{ 3. Timing of annual extreme water conditions } & Julian data of annual 1-day minimum & \multirow{2}{*}{$\begin{array}{l}\text { Provide special habitats during reproduction or to avoid predation; influences } \\
\text { spawning for migratory fish, evolution of life history strategies }\end{array}$} \\
\hline & Julian data of annual 1-day maximum & \\
\hline \multirow{4}{*}{ 4. Frequency and duration of high/low pulses } & Number of low pulses each year & \multirow{4}{*}{$\begin{array}{l}\text { Connection to soil moisture and anaerobic stress for plants; } \\
\text { Provide floodplain habitats; ensure nutrient and organic matter exchanges } \\
\text { between river and floodplain, soil mineral availability } \\
\text { Influences bedload transport, channel sediment textures and duration of } \\
\text { substrate disturbance (high pulses) }\end{array}$} \\
\hline & Mean duration of low pulses (d) & \\
\hline & Number of high pulses each year & \\
\hline & Mean duration of high pulses (d) & \\
\hline 5. Rate/frequency of flow condition changes & $\begin{array}{l}\text { Rise rate } \\
\text { Fall rate } \\
\text { Number of reversals }\end{array}$ & $\begin{array}{l}\text { Drought stress on plants (falling levels) } \\
\text { Entrapment of organisms on islands, floodplains (rising levels) } \\
\text { Desiccation stress on low-mobility stream edge (varial zone) organisms }\end{array}$ \\
\hline
\end{tabular}


In this study, the conventional RVA method and the updated methods considering the process changing behaviors of each of the indicators are shown in Sections 2.3.3-2.3.5.

\subsubsection{Accounting for Alteration of Indicators in the RVA}

In the RVA method [1], the degree of alteration for hydrologic indicator $m, D_{m}$, is used to measure the deviation of the post-impact flow regime from the natural regime, which is defined as follows:

$$
D_{m}=\left|\frac{N_{o m}-N_{e m}}{N_{e m}}\right| \times 100 \%
$$

where, $N_{o m}$ is the observed number of post-impact years in which the value of indicator $m$ falls within its RVA target range and $N_{e m}$ is the expected number of post-impact years in which the indicator value falls within the RVA target range (i.e., between the 75th and 25th percentiles for the natural daily flows). Then the average degree of alteration for these hydrologic indicators is applied to quantify the overall impact on the riverine system, which is expressed as follows:

$$
D=\frac{1}{H} \sum_{m=1}^{H} D_{m}
$$

where, $D$ is the overall alteration degree of the flow regime and $H$ is the number of the hydrologic parameters. The higher the value of $D$, the greater the degree of alteration. $33 \%$ and $66 \%$ are defined as the thresholds to distinguish low (0-33\%), medium (33-66\%) and high alteration ( $>66 \%)$.

\subsubsection{Accounting for the Alteration of Indicators Based on the Concept of Similarity/Diversity}

\section{- A Method Based on Euclidean Distance}

It is known that the RVA method concentrates on considering the frequency of indicators falling within the target range, whereas neglecting the process of indicators deviating from the target range. In this work, the method by Yin et al. [22] is employed and updated to measure the alteration induced by the process deviation.

$D F$ measures the difference between the pre-impact (denoted as $\left.A\left(a_{1}, a_{2}, \ldots a_{n}\right)\right)$ and post-impact time series (denoted as $B\left(b_{1}, b_{2}, \ldots b_{l}\right)$ ), where $q$ and $l$ represent the number of years within the pre-impact time series and duration of the post-impact period, respectively. $T$ is the maximum distance among the hydrologic year types (HYTs), which equals 2 when there are only three hydrologic year types (HYTs) categories.

$$
\begin{gathered}
\text { If } q=l, D F=\sqrt{\sum_{i=1}^{l}\left(a_{i}-b_{i}\right)^{2}} \\
\text { If } q>l, D F=\min \sqrt{\sum_{i=1}^{l}\left(a_{k+i}-b_{i}\right)^{2}}, k=0,1, \ldots, n-l \\
\text { If } q<l, D F=\min \sqrt{\sum_{i=1}^{n}\left(a_{i}-b_{k+1}\right)^{2}}, k=0,1, \ldots, l-n
\end{gathered}
$$

where min represents the minimum value of distance.

$S$ is the alteration degree of the HYT (hydrologic year types) order, which is the normalized value of the difference between two time series $(D F)$ :

$$
S=D F /\left[T \times \min \left(n^{1 / 2}, l^{1 / 2}\right)\right]
$$

for more details about the method, refer to Yin et al. [22]. 
In the study by Yin et al. [22], $S$ represents the alteration degree of the HYT order, which is integrated with the alteration degree evaluated by RVA. In this work, we made a modification on the method. We treat $S$ as the degree of alteration for time series of each indicator, instead of that for hydrologic year types (HYT). We can get two time series $A\left(a_{1}, a_{2}, \ldots a_{q}\right)$ and $B\left(b_{1}, b_{2}, \ldots b_{l}\right)$ to represent pre-impact and post-impact periods for each indicator. The time series of each indicator are normalized: values lower than the 25 th percentile, between the 25th percentile and 75 th percentile and larger than the 75th percentile, are assigned 0, 1 and 2, respectively. Note that the thresholds (25th percentile and 75th percentile) used here are calculated using the pre-impact series data. We can then obtain that $\left|a_{i}-b_{i}\right|=0$, or $\left|a_{i}-b_{i}\right|=1$, or $\left|a_{i}-b_{i}\right|=2$. $S$ for each IHA $\left(S_{m}\right)$ thereafter can be calculated. The overall alteration degree $(S)$ of the flow regime can be calculated by averaging $S_{m}$, which can be referred to Equation (5). Same to that used in RVA, 33\% and $66 \%$ are defined as the thresholds to distinguish low $(0-33 \%)$, medium (33-66\%) and high alteration $(>66 \%)$.

\section{- A method Based on Dynamic Time Warping (DTW) Distance}

The dynamic time warping (DTW) distance is a technique that finds the optimal alignment between two time series if one time series may be "warped" non-linearly by stretching or shrinking it along its time axis [45]. DTW is often used to determine time series similarity, classification and to find corresponding regions between two time series [46]. It is often used in speech recognition to determine if two waveforms represent the same spoken phrase. In a speech waveform, the duration of each spoken sound and the interval between sounds are permitted to vary, but the overall speech waveforms must be similar. In addition to speech recognition, dynamic time warping has also been found useful in many other disciplines [47], including data mining, gesture recognition, robotics, manufacturing and medicine. It is commonly used in data mining as a distance measure between time series [48].

The dynamic time warping problem is stated as follows [49]: Given two time series $X$ and $Y$,

$$
\begin{aligned}
& X=x_{1}, x_{2}, \ldots, x_{n} \\
& Y=y_{1}, y_{2}, \ldots, y_{m}
\end{aligned}
$$

construct a warp path $W$ :

$$
W=w_{1}, w_{2}, \ldots, w_{K} \max (m, n) \leq K<m+n
$$

where $K$ is the length of the warp path and the $k$ th element of the warp path is

$$
w_{k}=(i, j)
$$

where $i$ is an index of time series $X$, and $j$ is an index of time series $Y$. The warp path must start at the beginning of each time series at $w_{1}=(1,1)$ and finish at the end of both time series at $w_{k}=(m, n)$. Every index of each time series must be used, which is stated as follows:

$$
w_{k}=(i, j), w_{k+1}=\left(i^{\prime}, j^{\prime}\right) i \leq i^{\prime} \leq i+1, j \leq j^{\prime} \leq j+1
$$

Since a single point may map to multiple points in the other time series, the time series do not need to be of equal length, which is more advanced than Euclidean distance. If $X$ and $Y$ were identical time series, the warp path through the matrix would be a straight diagonal line. The optimal warp path is the warp path with the minimum distance, where the distance of a warp path $W$ is:

$$
\operatorname{Dist}(W)=\sum_{k=1}^{k=K} \operatorname{Dist}\left(w_{k i}, w_{k j}\right)
$$


$\operatorname{Dist}(W)$ is the distance (typically a Euclidean distance) of the warp path $W$, and $\operatorname{Dist}\left(w_{k i}, w_{k j}\right)$ is the distance between the two data point indices (one from $X$ and one from $Y$ ) in the $k$ th element of the warp path.

The rationale of the DTW algorithm to find the minimum-distance warp path is a dynamic programming approach. For more details about the algorithm, please refer to Salvador and Chan. [49].

In this work, the state-of-the-art FastDTW method is employed to identify the similarity of pre-impact and post-impact series. It can be used on much larger data sets than DTW. Standard dynamic time warping (DTW) is an $\mathrm{O}\left(N^{2}\right)$ algorithm because every cell in the cost matrix must be filled to ensure an optimal answer is found, and the size of the matrix grows quadratically with the size of the time series. In FastDTW, the cost matrix is only filled in the neighborhood of the path projected from the previous resolution. The length of the warp path grows linearly with the size of the input time series, the multilevel approach is thus an $\mathrm{O}(N)$ algorithm. FastDTW is an order of magnitude faster than DTW, and it also compliments existing indexing methods that speed up time series similarity search and classification. For more details about FastDTW, please refer to Salvador and Chan. [49].

The inputs here are pre-impact and post-impact series of each indicator, and they are normalized through the method shown above. That is to say, the values of each indicator are normalized to 0,1 and 2. The outputs are a warp path $(W)$ and a distance between two time series along that warp path (Dist). Dist is the accumulated distance of the warp path, indicating similarity/diversity of the two sequential data (pre-impact and post-impact series). In this work, we normalize it using the following Equation:

$$
S D_{m}=\text { Dist } /[T \times K]
$$

where $T$ is the maximum distance between the two data point indices (one from $X$ and one from $Y$ ), which equals to 2 in this case. $K$ is length (number) of the warp path. $S D_{m}$ is the alteration degree induced by the process differences of the pre- and post-impact time series for each indicator. The overall alteration degree $(S D)$ of the flow regime can be calculated by averaging $S D_{m}$, which can be referred to from Equation (5). It describes the features of post-impact indicators deviating from the natural flow regimes. It ranges between 0 and 1 . The larger the value of $S D$, the greater the degree of alteration and more serious the degradation of the riverine ecosystem. Same to that used in RVA, $33 \%$ and $66 \%$ are defined as the thresholds to distinguish low $(0-33 \%)$, medium (33-66\%) and high alteration $(>66 \%)$.

\subsubsection{Integrated Measure for Alteration Degree of Flow Regime}

The RVA will underestimate the degree of flow regime alteration in terms of that only frequency is considered to represent the degree [22], i.e., the difference between the proportion of pre-impact and post-impact values falling within the target range is considered to represent the degree of alteration. In this work, we develop two integrated metrics based on the equation proposed by Yin et al. [22]:

$$
O D=1-[(1-D) \times(1-M)]
$$

where $O D$ varies between 0 and 1 . The greater the value of $O D$, the more serious the degradation of the riverine ecosystem. In the study by Yin et al. [22], $D$ is the alteration degree by RVA, and $M$ is the alteration degree of the HYT (hydrologic year types) order.

In this work, we deem $D$ as the alteration degree representing frequency features, and $M$ is the degree representing process features. $O D$ is the degree of alteration considering both changes in frequency and process. Therefore, two integrated metrics are developed as follows:

$$
\begin{gathered}
O D \_S=1-[(1-D) \times(1-S)] \\
O D \_S D=1-[(1-D) \times(1-S D)]
\end{gathered}
$$


where $D$ is the alteration degree calculated by RVA, $S$ is the degree calculated by the method based on Euclidean distance (Equation (9)), and SD is the degree calculated by the method based on FastDTW (Equation (16)). These two Equations can be used both in estimating the overall alteration degree for all indicators and in estimating the degree for each indicator. When it is used to estimate the degree for each indicator, $\left|D_{m}\right|, S_{m}$ and $S D_{m}$ should be used instead of $D, S$ and $S D$. Same to that used in RVA, $33 \%$ and $66 \%$ are defined as the thresholds to distinguish low $(0-33 \%)$, medium (33-66\%) and high alteration $(>66 \%)$.

\section{Results}

\subsection{Changes in Annual Mean Streamflow}

The Mann-Kendall test method (M-K) is employed to examine abrupt changes in annual mean streamflow at the Zhangjiashan Station. Figure 3 shows the test for abrupt changes in annual streamflow. It suggests that a significant abrupt change point occurs after 1996. The annual mean streamflow before and after 1996 is $57.84 \mathrm{~m}^{3} / \mathrm{s}$ and $31.35 \mathrm{~m}^{3} / \mathrm{s}$, respectively. The variation amplitude is $-45.80 \%$. Additionally, the results by $\mathrm{M}-\mathrm{K}$ suggest that the annual mean streamflow tends to slightly increase during the period 1960-1970 and decrease after 1970. There is an intersection of $U F_{k}$ and $U B_{k}$ between the value of 1996 and 1997, indicating that a sharp decrease appears after 1996 and the decreasing trend is significant after 1997 (Sig. $=0.05$ ).

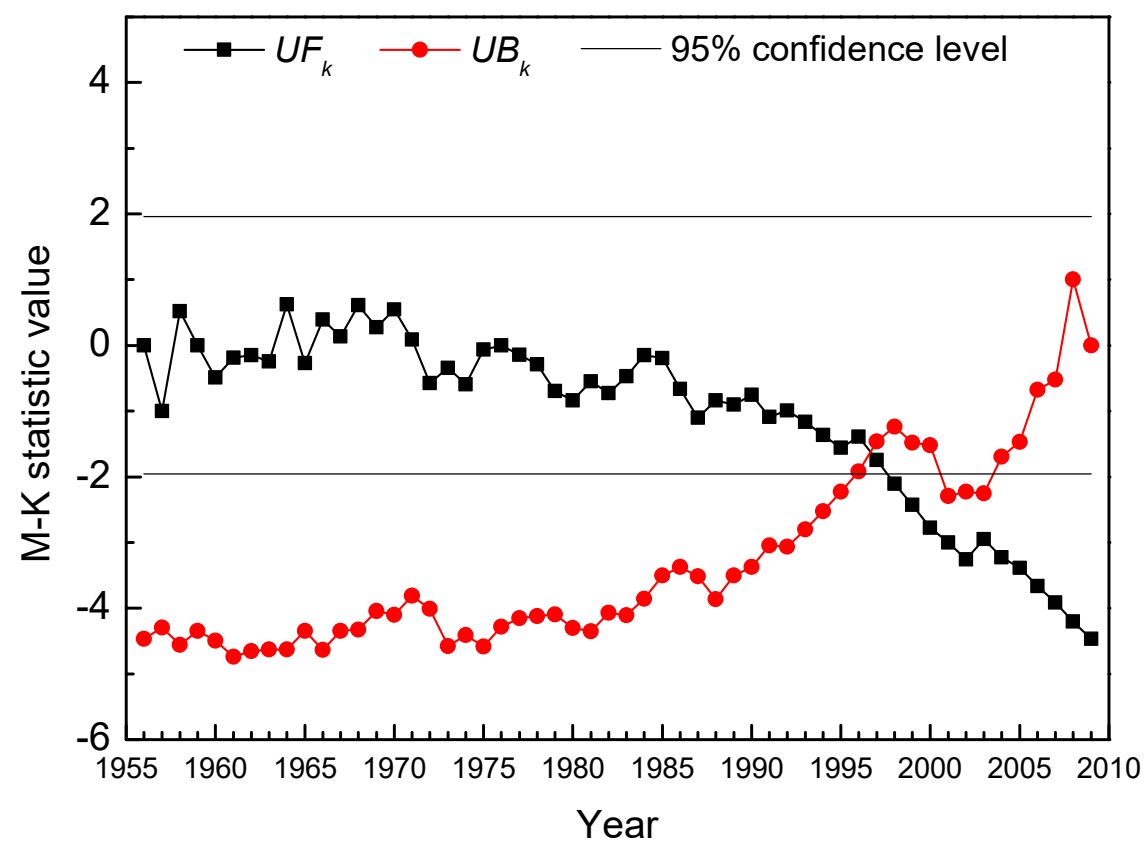

Figure 3. Statistical test for abrupt changes in annual streamflow (There is an intersection point of the $U F$ and $U B$ lines after year 1996, suggesting an abrupt point).

\subsection{Changes in the Hydrologic Parameters}

As shown in Table 2, the streamflow of each month obviously decreases, especially during the wet season. There is an average of $51.36 \%$ reduction for the median values of streamflow in June, July, August and September, while the reduction is $38.63 \%$ in the dry season. The large amount of reduction of monthly flow indicates an obvious decrease of water resources in the basin. 
Table 2. Variation and degree of alteration for hydrologic parameters.

\begin{tabular}{|c|c|c|c|c|}
\hline \multirow{2}{*}{ Group } & \multirow{2}{*}{ Hydrologic Parameters } & \multicolumn{2}{|c|}{ Median } & \multirow[b]{2}{*}{ Variation } \\
\hline & & Pre-Impact & Post-Impact & \\
\hline \multirow{12}{*}{1} & Mean discharge for January & 18.6 & 14.13 & $-24.03 \%$ \\
\hline & Mean discharge for February & 28.6 & 18.7 & $-34.62 \%$ \\
\hline & Mean discharge for March & 39.7 & 21.7 & $-45.34 \%$ \\
\hline & Mean discharge for April & 31.85 & 13.85 & $-56.51 \%$ \\
\hline & Mean discharge for May & 25.1 & 15.4 & $-38.65 \%$ \\
\hline & Mean discharge for June & 25.75 & 14 & $-45.63 \%$ \\
\hline & Mean discharge for July & 50 & 25.6 & $-48.80 \%$ \\
\hline & Mean discharge for August & 67.8 & 30.9 & $-54.42 \%$ \\
\hline & Mean discharge for September & 53.3 & 23.15 & $-56.57 \%$ \\
\hline & Mean discharge for October & 44.7 & 29.9 & $-33.11 \%$ \\
\hline & Mean discharge for November & 36.9 & 21.55 & $-41.60 \%$ \\
\hline & Mean discharge for December & 23.9 & 15.5 & $-35.15 \%$ \\
\hline \multirow{11}{*}{2} & Minimum 1-day & 9.84 & 1.48 & $-84.96 \%$ \\
\hline & Minimum 3-day & 10.5 & 3.183 & $-69.69 \%$ \\
\hline & Minimum 7-day & 11.84 & 5.863 & $-50.48 \%$ \\
\hline & Minimum 30-day & 16.51 & 10.13 & $-38.64 \%$ \\
\hline & Minimum 90-day & 21.92 & 13.83 & $-36.91 \%$ \\
\hline & Maximum 1-day & 792 & 535 & $-32.45 \%$ \\
\hline & Maximum 3-day & 515.3 & 363 & $-29.56 \%$ \\
\hline & Maximum 7-day & 307.9 & 174.9 & $-43.20 \%$ \\
\hline & Maximum 30-day & 158.8 & 83.77 & $-47.25 \%$ \\
\hline & Maximum 90-day & 102.1 & 58.06 & $-43.13 \%$ \\
\hline & Base-flow index & 0.204 & 0.140 & $-31.37 \%$ \\
\hline \multirow{2}{*}{3} & Julian data of annual 1-day minimum & 168 & 178 & 10 day \\
\hline & Julian data of annual 1-day maximum & 217 & 214 & -3 day \\
\hline \multirow{4}{*}{4} & Number of low pulses each year & 10 & 19 & $90 \%$ \\
\hline & Mean duration of low pulses (day) & 4 & 3.5 & -0.5 day \\
\hline & Number of high pulses each year & 12 & 10 & $-16.67 \%$ \\
\hline & Mean duration of high pulses (day) & 3 & 2 & -1 day \\
\hline \multirow{3}{*}{5} & Rise rate & 2.6 & 2.6 & $0 \%$ \\
\hline & Fall rate & -2.7 & -3 & $-11.11 \%$ \\
\hline & Number of reversals & 136 & 168 & $23.53 \%$ \\
\hline
\end{tabular}

Figure 4 shows the changes in magnitude of annual extreme discharge events with different durations. All the minimum indicators have a decreasing trend (Figure 4a). Compared with the mean values in the pre-impact period, the annual 1-day, 3-day, 7-day, 30-day and 90-day minimum flows in the post-impact period decrease by $84.96 \%, 69.69 \%, 50.48 \%, 38.64 \%$, and $36.91 \%$, respectively (Table 2 ). As to the maximum metrics, a decrease occurs as well (Figure $4 \mathrm{~b}$ ).

The variations of 1-day and 3-day maximum flows are lower than that of 7-day, 30-day and 90-day maximum flows. Decrease is also found for the base-flow index (Figure 4a and Table 2). 


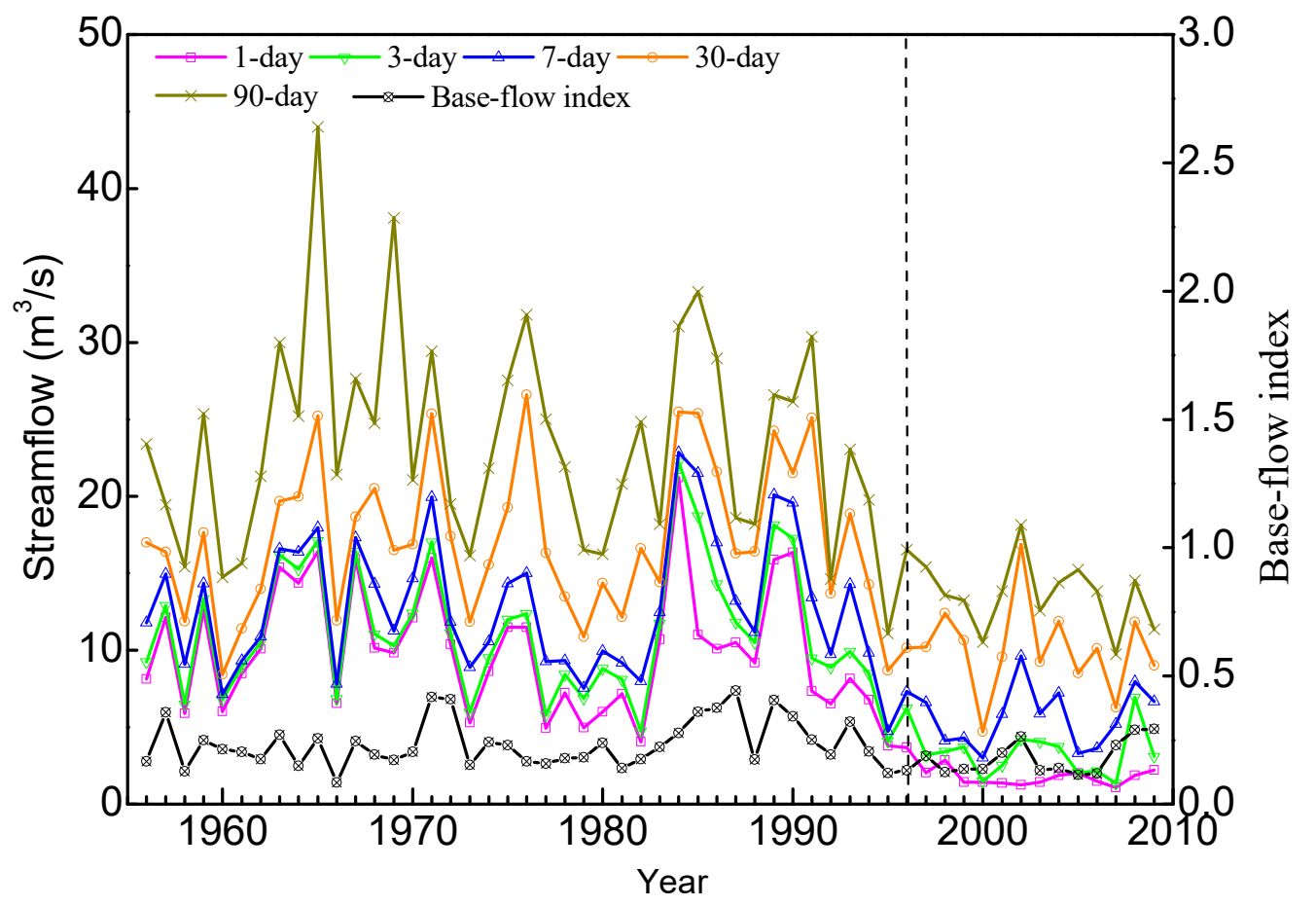

(a)

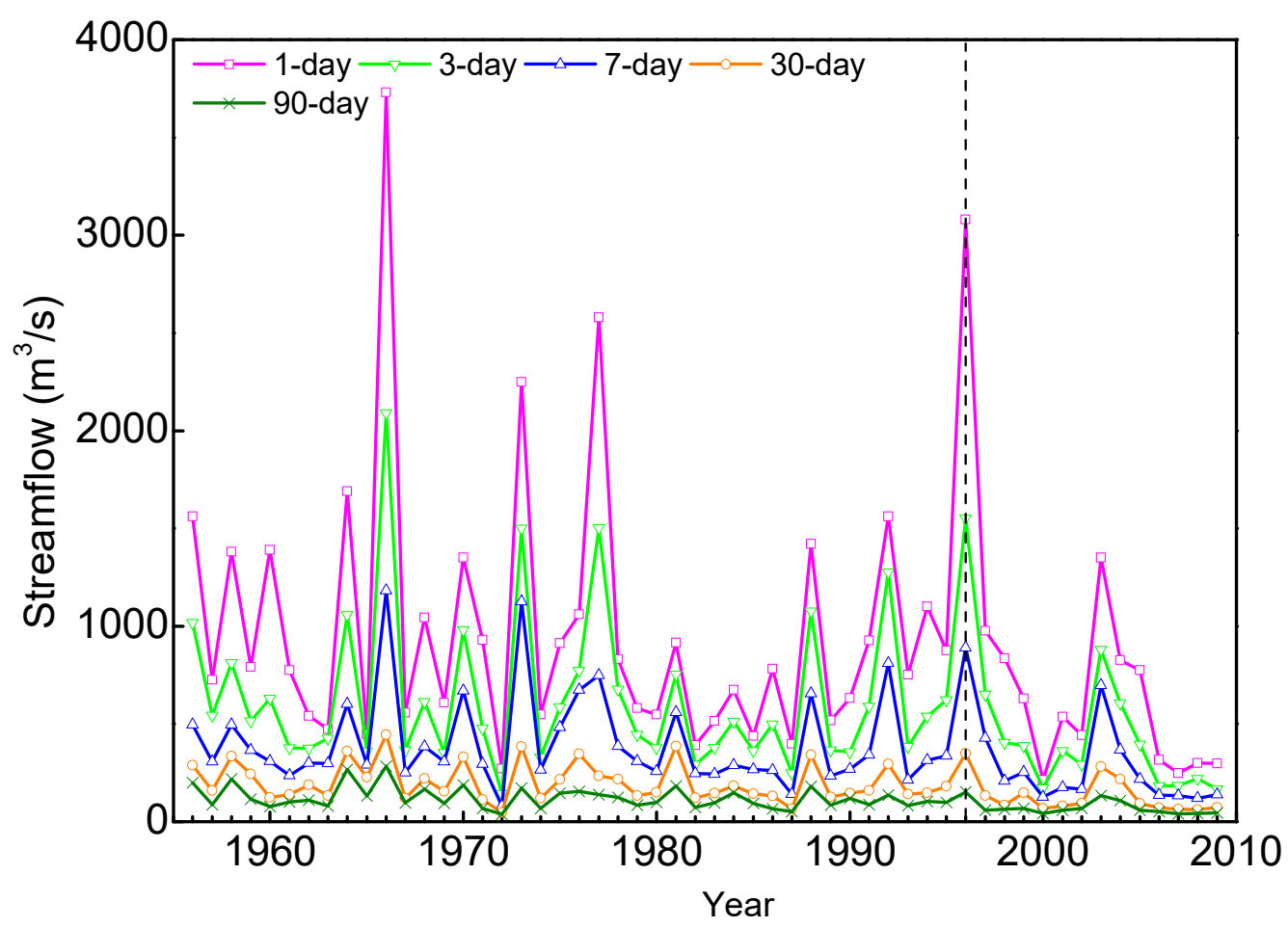

(b)

Figure 4. Changes in the magnitude of (a) annual minimum flow and (b) annual maximum flow with different durations at Zhangjiashan Station (the outlet of the Jinghe Basin).

Figure 5 shows the timing of annual extreme water conditions. As to the annual 1-day minimum flow, it occurs in almost every month during the pre-impact period except November and March (Figure 5a). It frequently occurs in May, June and July, and the median of the occurrence happens 
in June (Figure 5a). In comparison, the median occurrence of 1-day minimum flow in post-impact period delays 10 days (Figure 5b). For the annual 1-day maximum flow, it occurs from May to October in the pre-impact period, which mainly concentrates in July and August (Figure 5c). The median locates in August. In comparison, the median occurrence in the post-impact period advances three days (Figure $5 d$ ).

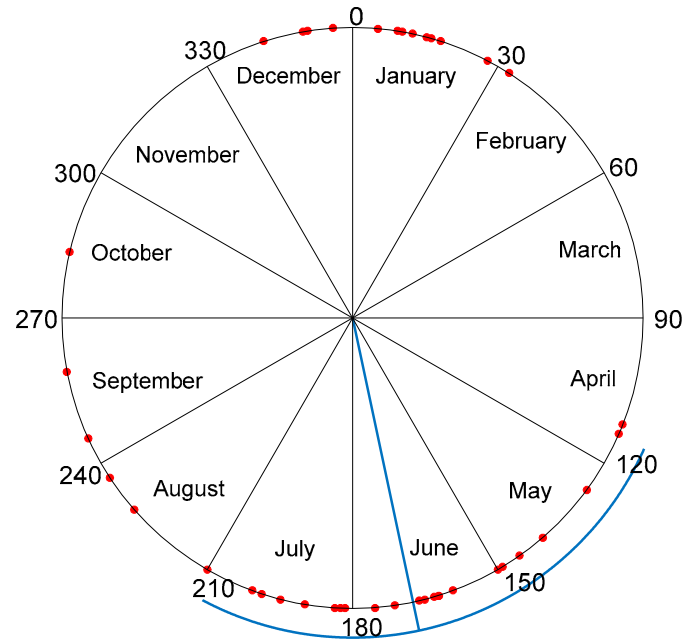

(a)

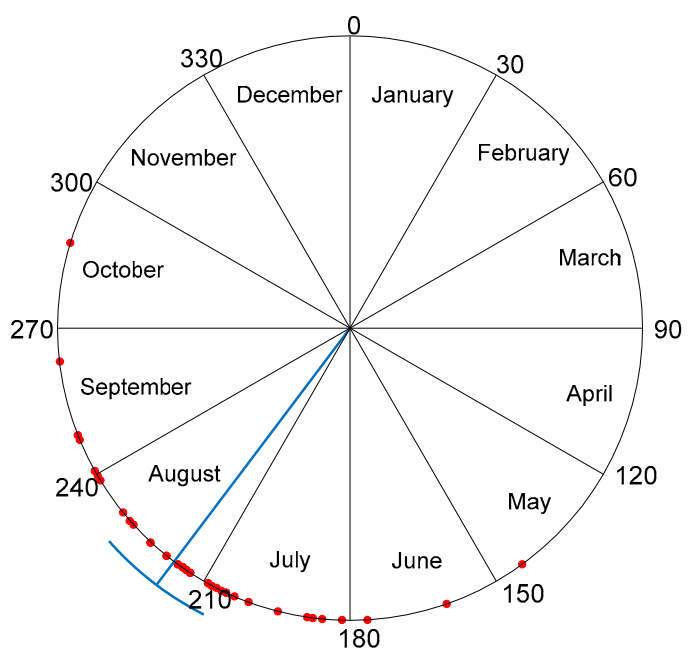

(c)

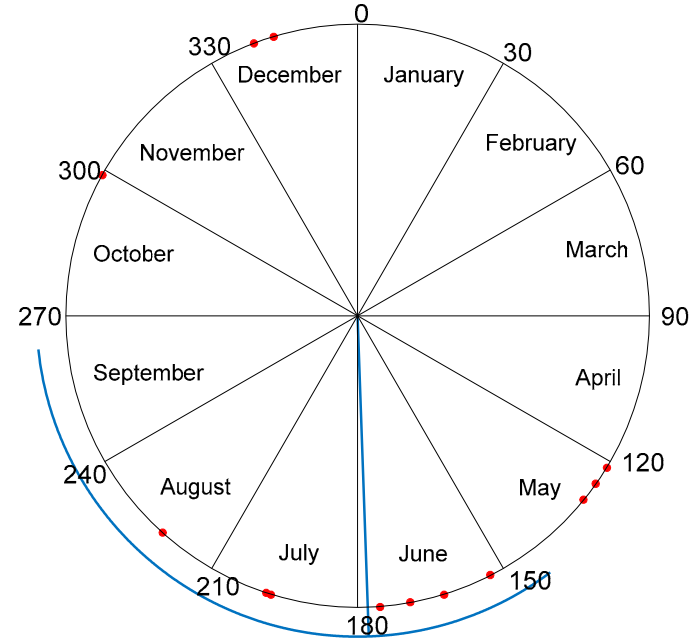

(b)

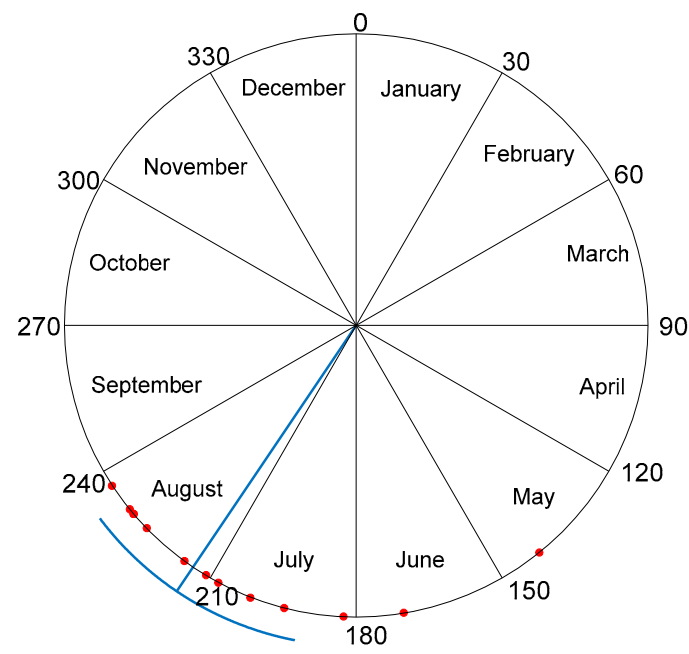

(d)

Figure 5. Timing of annual 1-day minimum in (a) the pre-impact period and (b) the post-impact period, and the timing of annual 1-day maximum in (c) the pre-impact period and (d) the post-impact period.

Figure 6 shows the number and duration of low and high pulses within each year. The number of low pulses within each year has an obvious growing trend (Figure 6a). The median in the post-impact period increases by $90 \%$ compared with that in the pre-impact period (Table 2). Mean duration of low pulses in the post-impact period decreases by 0.5 day compared with that in the pre-impact period (Table 2). As to the high pulses, the median number in this post-impact period reduces $16.67 \%$ compared with that in our pre-impact period (Table 2). Mean duration of high pulses reduces by 1 day (Table 2). 


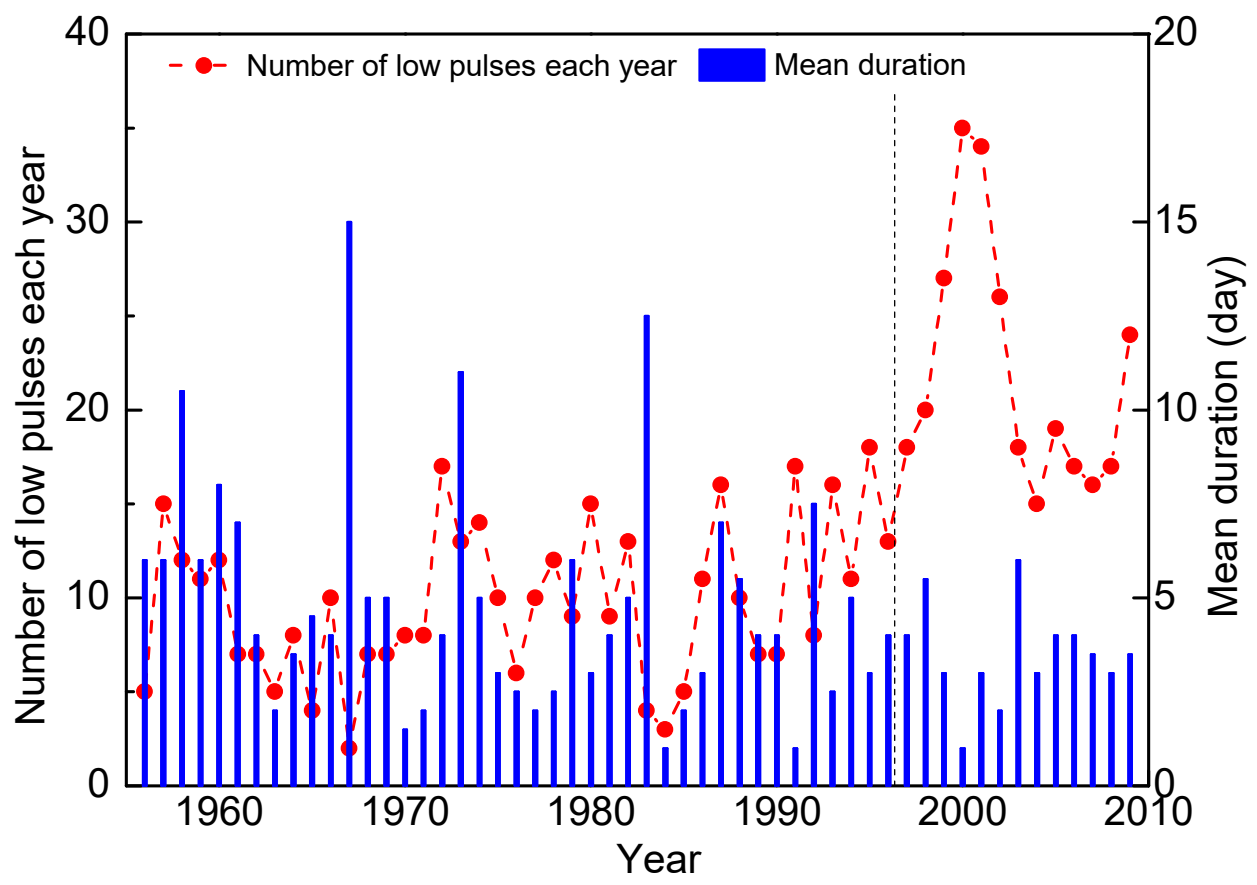

(a)

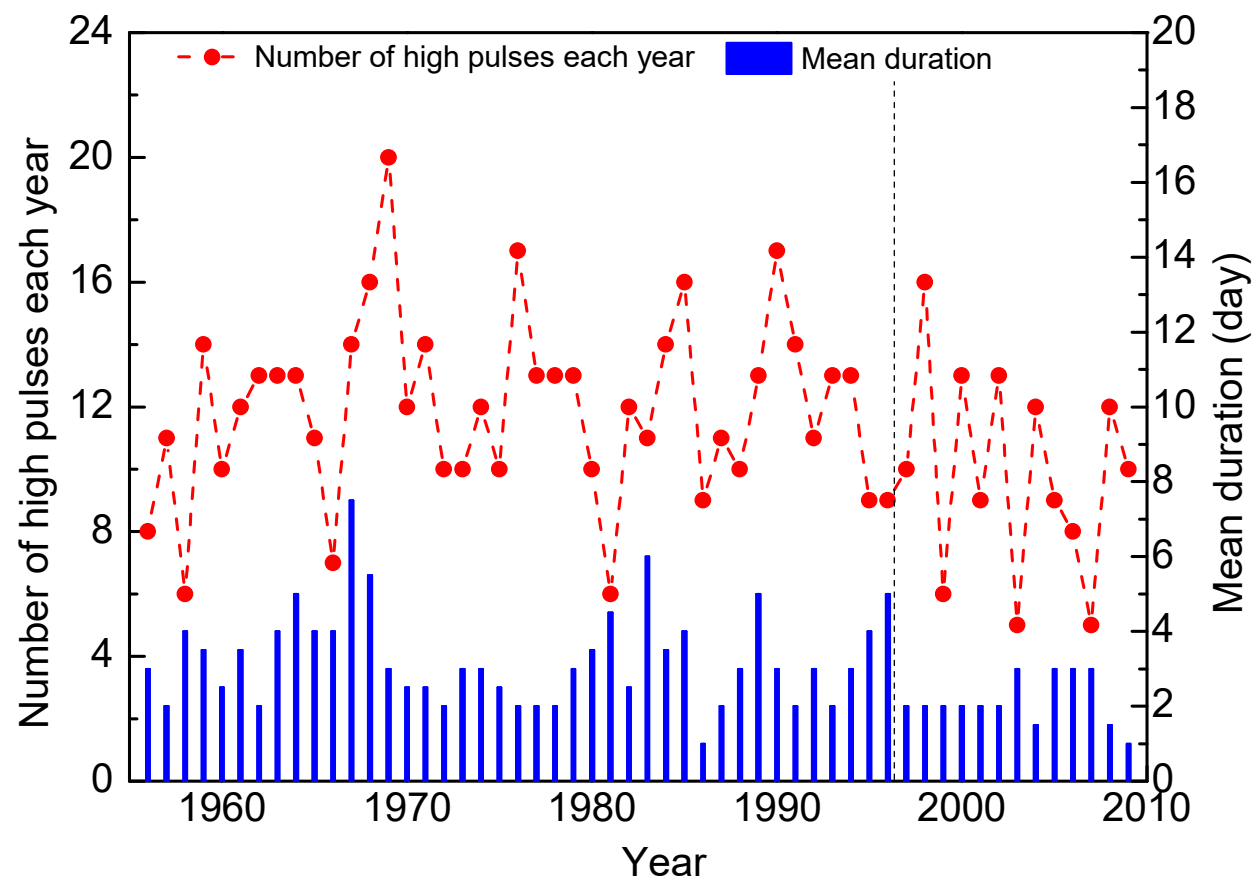

(b)

Figure 6. Number and mean duration of (a) low and (b) high pulses each year at Zhangjiashan Station (the outlet of Jinghe Basin).

Figure 7 shows the rise rate, fall rate and number of reversals. The median rise rate in the post-impact period is consistent with that in the pre-impact period, and no change $(0 \%)$ is found for the median values (Table 2). The median fall rate in the post-impact period has $11.11 \%$ reduction compared with that in the pre-impact period (Table 2). As to the number of reversals, the median in this post-impact period increases by $23.53 \%$ compared to that in our pre-impact period (Table 2). 


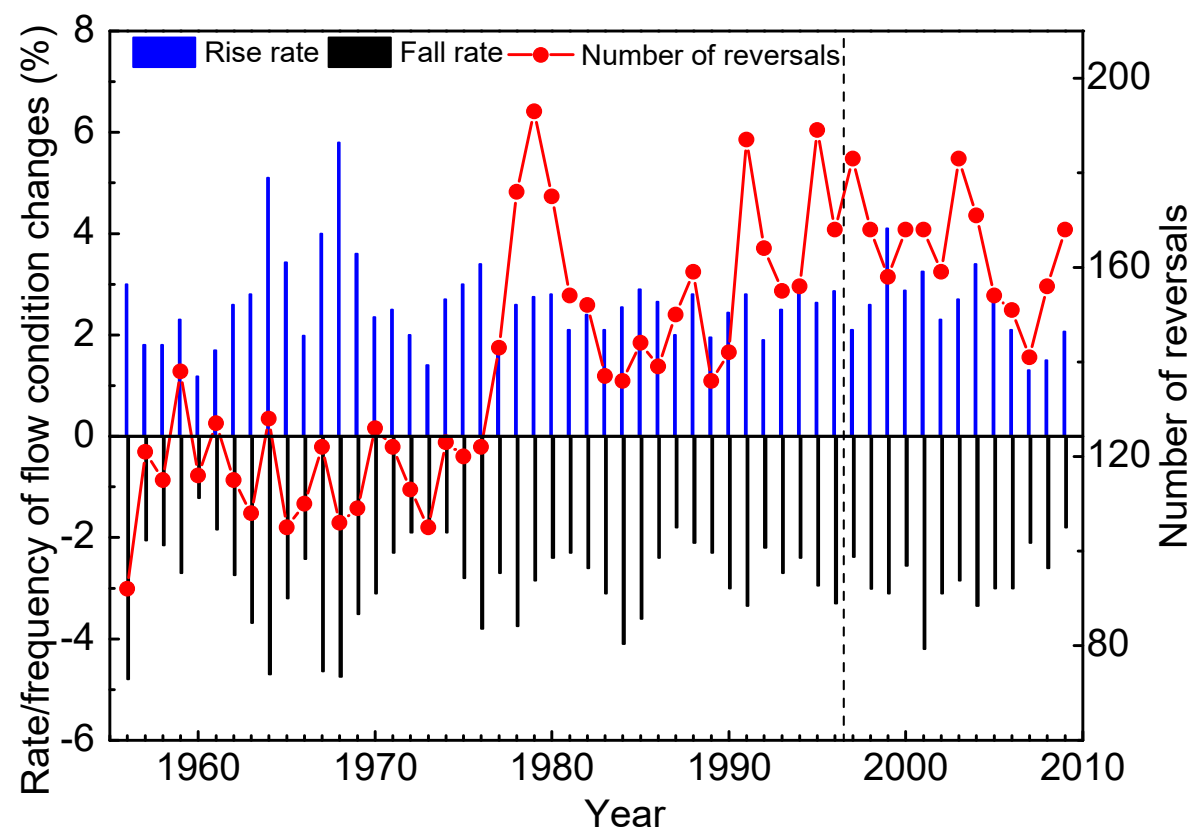

Figure 7. Rise rate, fall rate and number of reversals at Zhangjiashan Station (the outlet of the Jinghe Basin).

\subsection{Alteration Degree of the Hydrologic Parameters}

The alteration degrees by five metrics (i.e., $D, S, S D, O D \_S$, and $O D \_S D$, including three single metrics and two composite metrics) for each hydrologic parameter are shown in Figure 8a and Table 3. The alteration degrees for 32 hydrologic parameters by each assessment method are aggregated as box-plots and are shown in Figure 8 b.

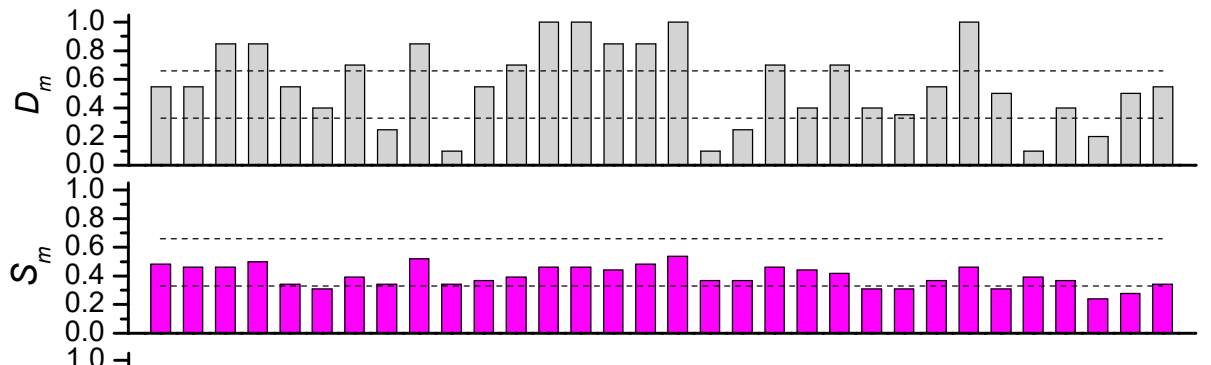
क $\begin{gathered}1.0 \\ 0.6\end{gathered}$

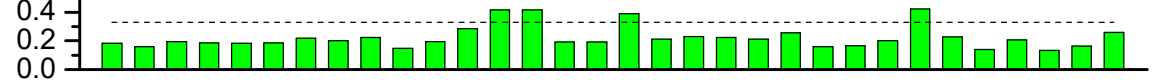

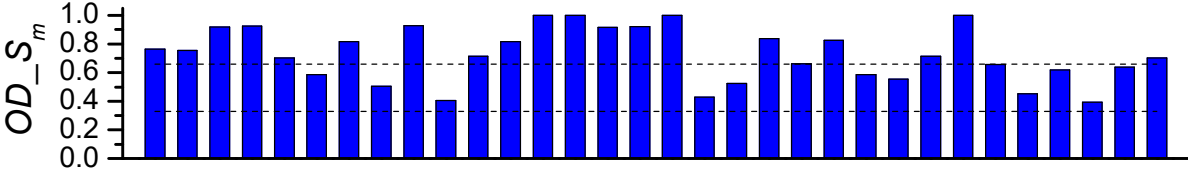

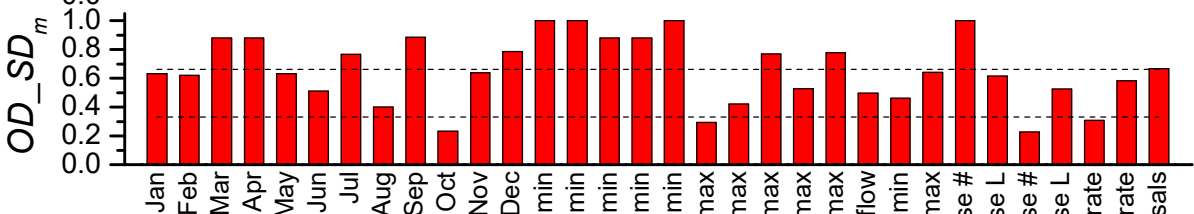

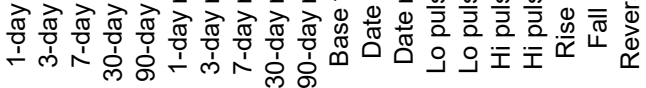

(a)

Figure 8. Cont. 


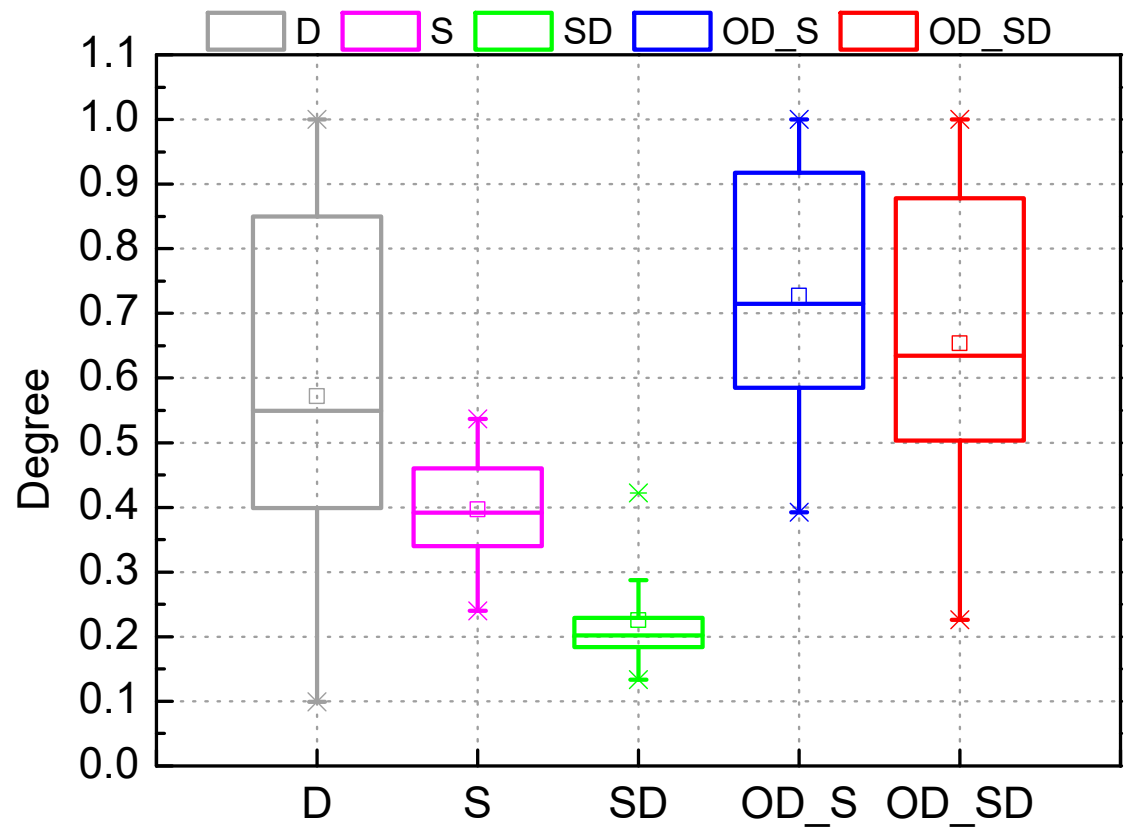

(b)

Figure 8. (a) Alteration degrees by five measures (i.e., $D, S, S D, O D \_S$, and $O D \_S D$, including three single measures and two composite measures) for each hydrologic parameter, (b) Alteration degree of the 32 hydrologic parameters by five assessment methods.

Table 3. Alteration degree of the 32 hydrologic parameters.

\begin{tabular}{|c|c|c|c|c|c|c|}
\hline Group & Hydrologic Parameters & $D_{m}$ & $S_{m}$ & $S D_{m}$ & $O D \_S_{m}$ & $O D \_S D_{m}$ \\
\hline \multirow{12}{*}{1} & Mean discharge for January & -0.55 & 0.48 & 0.18 & 0.77 & 0.63 \\
\hline & Mean discharge for February & -0.55 & 0.46 & 0.16 & 0.76 & 0.62 \\
\hline & Mean discharge for March & -0.85 & 0.46 & 0.20 & 0.92 & 0.88 \\
\hline & Mean discharge for April & -0.85 & 0.50 & 0.19 & 0.93 & 0.88 \\
\hline & Mean discharge for May & -0.55 & 0.34 & 0.18 & 0.70 & 0.63 \\
\hline & Mean discharge for June & -0.40 & 0.31 & 0.19 & 0.59 & 0.51 \\
\hline & Mean discharge for July & -0.70 & 0.39 & 0.22 & 0.82 & 0.77 \\
\hline & Mean discharge for August & -0.25 & 0.34 & 0.20 & 0.50 & 0.40 \\
\hline & Mean discharge for September & -0.85 & 0.52 & 0.22 & 0.93 & 0.88 \\
\hline & Mean discharge for October & -0.10 & 0.34 & 0.15 & 0.41 & 0.23 \\
\hline & Mean discharge for November & -0.55 & 0.37 & 0.20 & 0.71 & 0.64 \\
\hline & Mean discharge for December & -0.70 & 0.39 & 0.29 & 0.82 & 0.79 \\
\hline \multirow{11}{*}{2} & Minimum 1-day & -1.00 & 0.46 & 0.42 & 1.00 & 1.00 \\
\hline & Minimum 3-day & -1.00 & 0.46 & 0.42 & 1.00 & 1.00 \\
\hline & Minimum 7-day & -0.85 & 0.44 & 0.19 & 0.92 & 0.88 \\
\hline & Minimum 30-day & -0.85 & 0.48 & 0.19 & 0.92 & 0.88 \\
\hline & Minimum 90-day & -1.00 & 0.54 & 0.39 & 1.00 & 1.00 \\
\hline & Maximum 1-day & -0.10 & 0.37 & 0.21 & 0.43 & 0.29 \\
\hline & Maximum 3-day & -0.25 & 0.37 & 0.23 & 0.52 & 0.42 \\
\hline & Maximum 7-day & -0.70 & 0.46 & 0.22 & 0.84 & 0.77 \\
\hline & Maximum 30-day & -0.40 & 0.44 & 0.21 & 0.66 & 0.53 \\
\hline & Maximum 90-day & -0.70 & 0.42 & 0.26 & 0.82 & 0.78 \\
\hline & Base-flow index & -0.40 & 0.31 & 0.16 & 0.59 & 0.49 \\
\hline
\end{tabular}


Table 3. Cont.

\begin{tabular}{|c|c|c|c|c|c|c|}
\hline Group & Hydrologic Parameters & $D_{m}$ & $S_{m}$ & $S D_{m}$ & $O D \_S_{m}$ & $O D \_S D_{m}$ \\
\hline \multirow[b]{2}{*}{3} & Julian data of annual 1-day minimum & 0.35 & 0.31 & 0.17 & 0.55 & 0.46 \\
\hline & Julian data of annual 1-day maximum & -0.55 & 0.37 & 0.20 & 0.71 & 0.64 \\
\hline \multirow{4}{*}{4} & Number of low pulses each year & -1.00 & 0.46 & 0.42 & 1.00 & 1.00 \\
\hline & Mean duration of low pulses (d) & 0.50 & 0.31 & 0.23 & 0.66 & 0.62 \\
\hline & Number of high pulses each year & -0.10 & 0.39 & 0.14 & 0.45 & 0.23 \\
\hline & Mean duration of high pulses (d) & -0.40 & 0.37 & 0.21 & 0.62 & 0.52 \\
\hline \multirow{3}{*}{5} & Rise rate & 0.20 & 0.24 & 0.13 & 0.39 & 0.31 \\
\hline & Fall rate & 0.50 & 0.28 & 0.16 & 0.64 & 0.58 \\
\hline & Number of reversals & -0.55 & 0.34 & 0.26 & 0.70 & 0.67 \\
\hline \multirow{2}{*}{ Overall } & & $D$ & $S$ & $S D$ & OD_S & $O D \_S D$ \\
\hline & & 0.57 & 0.40 & 0.23 & 0.74 & 0.67 \\
\hline
\end{tabular}

\subsubsection{Alteration of Monthly Streamflow}

It is seen in Figure 8a that $D_{m}$ values for the monthly streamflow suggest almost all of them show moderate and high levels of their degree of alteration, except the streamflow of August and October (low level degree).

The $S_{m}$ values indicate that 11 parameters present a moderate level degree and 1 parameter (June) shows a low level degree. $S D_{m}$ values show a low level degree of alteration for all the 12 parameters, which are lower than those by $S_{m}$. As to the composite metrics, they show a larger degree than that by the individual ones. $O D \_S_{m}$ indicate all the 12 parameters have moderate or high degree of alteration. Monthly flow of June, August and October are altered with a moderate degree and the others with a high degree. $O D \_S D_{m}$ show a similar trend with $O D \_S_{m}$, but there are differences in the degree for five months. January, February, May and November show a moderate alteration degree by $O D_{-} S D_{m}$ while a high degree by $O D \_S_{m}$. October shows a low alteration degree by $O D \_S D_{m}$ while a moderate one by $O D \_S_{m}$.

\subsubsection{Alteration of Magnitude of Annual Extreme Streamflow}

It is seen in Figure 8a that the $D_{m}$ values for 1-day, 3-day, 7-day, 30-day and 90-day minimum flows indicate a high degree of alteration, $S_{m}$ values suggest a middle degree of alteration, and $S D_{m}$ values show moderate and low degrees of alteration. $O D \_S_{m}$ and $O D_{-} S D_{m}$ values show a high degree of alteration, which are consistent with the degree by $D_{m}$.

As to the maximum metrics, the $D_{m}$ values suggest that 1-day and 3-day maximum flows have low levels of alteration and 7-day, 30-day and 90-day maximum flows have both the high and moderate levels. The $S_{m}$ values suggest a moderate level of alteration for all the five parameters, while the $S D_{m}$ values show a consistent low level of alteration. $O D \_S_{m}$ and $O D_{-} S D_{m}$ show a consistent moderate degree for 3-day maximum flow and a high degree for 7-day and 90-day maximum flows, while different degrees for the 1-day maximum and 30-day maximum. In addition, for the base-flow index, $D_{m}$ indicates a moderate level of alteration, while $S_{m}$ and $S D_{m}$ suggest a consistent low level degree. $O D \_S_{m}$ and $O D \_S D_{m}$ consistently show a moderate degree.

\subsubsection{Alteration of Timing of Annual Extreme Water Conditions}

For the annual 1-day minimum flow, $D_{m}$ suggests a moderate level of alteration, and $S_{m}$ as well as $S D_{m}$ suggest low levels of alteration. Similar to that by $D_{m}, O D_{-} S_{m}$ and $O D_{-} S D_{m}$ show moderate degrees as well. For the annual 1-day maximum flow, $D_{m}$ and $S_{m}$ both suggest moderate levels of alteration, and $S D_{m}$ shows a low level of alteration. $O D_{-} S_{m}$ and $O D_{-} S D_{m}$ suggest high and middle degree, respectively. 


\subsubsection{Alteration of Frequency and Duration of High and Low Pulses}

As to the number of low pulses each year (denoted as Lo pulse \# in Figure 8a), $D_{m}$ suggests the high degree of alteration, while $S_{m}$ and $S D_{m}$ suggest a moderate degree. Both $O D_{-} S_{m}$ and $O D_{-} S D_{m}$ show a high alteration degree, which is same to that by $D_{m}$. For the mean duration of low pulses (denoted as Lo pulse L in Figure 8a), $D_{m}$ suggests a moderate degree, and $S_{m}$ and $S D_{m}$ suggest low degree of alteration. $O D \_S_{m}$ and $O D \_S D_{m}$ show high degree and moderate degree, respectively. As to the high pulses, low degree is detected for the median of number (denoted as Hi pulse \# in Figure 8a) by $D_{m}$ and $S D_{m}$, while a moderate degree by $S_{m}$.

The moderate degree is detected for a mean duration of high pulses (denoted as Hi pulse $\mathrm{L}$ in Figure 8a) by $D_{m}$ and $S_{m}$, while a low degree by $S D_{m}$. $O D_{-} S_{m}$ and $O D_{-} S D_{m}$ suggest moderate degrees for the mean duration of high pulses.

\subsubsection{Alteration of Streamflow Variability}

It is seen in Figure 8a that the median rise rate has low degrees of alteration detected by $D_{m}, S_{m}$, $S D_{m}$ and $O D_{-} S D_{m}$, and moderate degrees by $O D_{-} S_{m}$. The median fall rate has moderate degrees of alteration detected by $D_{m}, O D_{-} S_{m}$ and $O D_{-} S D_{m}$, and low degrees by $S_{m}$ and $S D_{m}$. As to the number of reversals, $D_{m}$ and $S_{m}$ suggest a moderate degree of alteration, $S D_{m}$ suggests a low degree of alteration, then $O D \_S_{m}$ and $O D \_S D_{m}$ suggest high degrees of alteration.

\subsubsection{Overall Alteration of Flow Regime}

According to Equation (5), the overall alteration of the flow regime was calculated (Table 3). The overall alteration degree of the basin is moderate level denoted by $D(0.57)$ and $S(0.40)$, and low level by $S D(0.23)$. OD_S (0.74) is the combination of $D$ and $S$, indicating a high degree of alteration. OD_SD $(0.67)$ is the combination of $D$ and $S D$, suggesting a high degree of alteration as well. These composite metrics consistently show that the basin suffered a high degree of alteration.

\subsection{Comparison of Alteration Degree by Different Methods}

It is seen in Figure 8a that there are differences in alteration degree measured by diverse methods. $D_{m}$ detected low degree for six parameters, moderate degree for 13 parameters and high degree for 13 parameters. $S_{m}$ detected low degree for six parameters and moderate degree for 26 parameters. $S D_{m}$ found low degree for 28 parameters and moderate degree for four parameters. To further show the difference of the alteration degree by different measures, we draw a box-plot to make a brief comparison (Figure $8 b$ ). It is seen that $D$ values range from 0.1 to 1.0 , indicating low, moderate and high alteration degrees for the 32 hydrologic parameters. $S$ values range from 0.24 to 0.54 , suggesting low and moderate alteration degrees. $S D$ values vary from 0.13 to 0.42 , most of which denote a low degree. $O D \_S$ ranges from 0.39 to 1.0 and $O D \_S D$ from 0.23 to 1.0, most of which suggest moderate and high levels of alteration.

Through a comparison between $D_{m}$ and $O D_{-} S D_{m}$, we can find a large similarity between them (Figure 8a). Almost all the hydrologic parameters show same alteration degree, except two parameters (monthly flow of August and 3-day maximum flow). $D_{m}$ shows a low degree for the monthly flow of August and a 3-day maximum flow, while $O D_{-} S D_{m}$ suggests a moderate level. It could be deemed that the increases of the level for these two parameters are induced by process changes of the time series. The overall alteration degree increases from middle level $(D=0.57)$ to high level $\left(O D \_S D=0.67\right)$.

Comparison between $D_{m}$ and $O D_{-} S_{m}$ reveals that the alteration degree of eight hydrologic parameters (that is, Jan, Feb, May, Nov, 30-day max, date max, Lo pulse L and reversals) increases from middle level to high level. Additionally, six hydrological parameters with low alteration degree by RVA (being August, October, 1-day max, 3-day max, high pulse \# and rise rate) tend to have moderate level alteration by $O D \_S_{m}$. The overall alteration degree increases from middle level $(D=0.57)$ to high level $\left(O D \_S=0.74\right)$. 


\section{Discussion}

Although there are differences amongst the values by individual metrics and the composite metrics, they are not contradictory. These metrics were constructed based on different concepts, describing different features of flow regime alteration. The objective of $D$ by the RVA method is to attain the targeted range at the same frequency as occurred in the natural or pre-impact flow regime. The RVA is useful for setting preliminary or interim flow targets for river reaches with highly altered hydrological regimes, i.e., where one or more annual streamflow characteristics frequently fall outside their historic ranges of variability [20].

As to the $S$ and $S D$, they are aimed to measure the deviation of the post-impact flow regime from the natural regime as well, which concentrates on describing the deviation of magnitude from the prospective of the process changes of IHAs. $S$ is calculated based on similarity/diversity concept by using Euclidean distance that measures the difference between pre-impact and post-impact hydrologic parameters. $S D$ is constructed based on this same similarity/diversity concept as well, which measures the difference by using the dynamic time warping distance. The advantage of $S D$ is that it does not require the same length of data for pre-impact and post-impact time series. Those two composite metrics $\left(O D \_S\right.$ and $\left.O D \_S D\right)$ capture the alteration induced both by frequency changes and process changes. That is to say, the difference between the proportions of pre-impact and post-impact values falling within the target range is considered, and the difference between the process behaviors of pre-impact and post-impact sequential data is considered as well.

The parameters for annual extreme flow (including 1-day min, 3-day min, 7-day min, 30-day min, 90-day min, 7-day max, 90-day max and Lo pulses \#) and some monthly flow (March, April, July, September and December) are characterized by a high alteration degree (denoted by the conventional RVA method). It indicates that these parameters are highly altered in terms of falling outside their historic ranges of variability. In addition, the parameters with moderate alteration (including January, February, May, November, 30-day max, date max, Lo pulse L and reversals) tend to have high level alteration when considering the process behaviors of their time series (denoted by $S_{m}$ ), indicating that these parameters alter, not only in appearance frequency of falling within historic ranges, but also in process behaviors, including magnitude and shape of time series.

On the other hand, two parameters (monthly flow of August and 3-day maximum flow) with low alteration degree (denoted by the conventional RVA method) tend to have a moderate alteration degree when considering the process behaviors of their time series (denoted by $S D_{m}$ ). Different to the effect by $S D_{m}$, the $S_{m}$ makes 14 hydrologic parameters increase by an alteration level (8 from moderate to high, 6 from low to moderate). It seems that the effect from $S_{m}$ is larger than that from $S D_{m}$, which is mainly because the values by $S_{m}$ are generally larger than that by $S D_{m}$. The difference between $S_{m}$ and $S D_{m}$ originates from the disparity of calculated distance between pre-impact and post-impact data series. However, what is similar, is that $S_{m}$ and $S D_{m}$ lead to a same level effect for the overall alteration degree. In other words, the overall alteration of the flow regime for the basin is at a moderate level measured by $D$, whereas at the high level when incorporated with $S_{m}$ or $S D_{m}$. The two aggregated metrics $\left(O D \_S\right.$ and $\left.O D \_S D\right)$ consistently suggest a high degree of alteration in the basin.

It was reported that the RVA underestimates the degree of flow regime alteration in terms of the fact that only frequency is considered to represent the degree [22]. Hence, the composite metrics are recommended to assess flow regime alteration, especially in the basin influenced both by climate change and human activities. Climate change and anthropogenic disturbance (including water withdraw, reservoir and check-dams construction, soil and water conservation practices) deeply influence flow regimes. A series of soil and water conservation practices have been carried out in the MRYR since the late 1950s, including engineering structures, such as terraces and dams, and biological measures such as afforestation and planting grass [31].

Afforestation and planting grass projects were implemented since the 1990s and intensified since the 2000s in the Jinghe Basin, leading to great changes in the riverine system. Consequently, both the 
changes in statistical features and in process features should be taken into account when assessing the alteration of flow regimes.

The two metrics $(S$ and $S D$ ) describing the process changes of IHAs suggest a different overall alteration level. The former one indicates a moderate level $(0.40)$ and the latter one the low level $(0.23)$. The disparity originates from the calculation for the distance between pre-impact and post-impact time series. A same length of data is necessary by measure $S$, thus the distance is calculated using the short one. It means that only a part of the data of the long one is used to make a comparison with the short one, which may overestimate the distance between two sequential data. As to the $S D$, it is constructed based on the dynamic time warping (DTW) distance. The time series inputs of pre-impact and post-impact do not need to be of equal length. Hence, $S D$ is more reasonable than $S$, and should be recommended when incorporated with $D$ generated by RVA.

The alteration of the flow regime has important effect on the ecological process and threatens the biodiversity and rivers ecosystem functions $[10,50]$. In this work, we mainly examine the implication of hydrological changes for the fish species. The community structure and index of biotic integrity (IBI) of the fish assemblage are good indicators of flow regime alteration under human disturbance and climate change [36]. Compared with the periphytic algae, zooplankter and aquatic higher plants, fish are at the top of the food chain. The fish are sensitive to environmental changes, which can comprehensively indicate the health level of the riverine water ecosystem.

Chinese scientists conducted investigations on the fish community structure and biological integrity in the Wei River Basin $\left(134,800 \mathrm{~km}^{2}\right.$, the largest tributary of the Yellow River) during 2011-2012 based on 55 sampling sites [36]. The ecosystem health was evaluated based on fish assemblages. The index of biotic integrity (IBI) for fish was used to assess the ecosystem health in the whole Wei River Basin (including the Wei River, Jinghe River, and Beiluo River). The integrity classes were classified into four groups: good, fair, poor and very poor. The results show that 7 of 13 sites (total 13 sites sampled in the Jinghe Basin) in the Jinghe Basin were in poor or very poor condition. In their field investigation in the Wei River Basin, 51 kinds of fish species were detected [36,37], and Cyprinidae and Cobitidae are the dominant fish species. Compared to the 58 kinds of fish in the last investigation during the 1980s, seven kinds of fish were extinct. As the largest tributary of the Wei River Basin, the Jinghe Basin has the lowest number of fish species and individuals. There are only 23 kinds of fish species in the Jinghe Basin, and the dominant species are Cobitidae (11 kinds) and Cyprinidae (9 kinds). Additionally, the Shannon-Weiner diversity index showed the least value in the Jinghe Basin.

The degradation of fish integrity can be explained from the prospective of an alteration of the flow regime. It is seen in Tables 2 and 4, all the indicators describing magnitude of flow (monthly flow and extreme flow) decrease obviously and the number of low pulses each year increases by $90 \%$, indicating the dry condition of the basin. It was reported that the index of biotic integrity (IBI) for fish was positively related to river depth $[35,36]$. Dissolved oxygen availability and water chemistry may be highly stressful to many organisms for low flow duration, leading to the increase of biotic interactions, such as competition and predation [51]. Some aquatic plants will be significantly reduced during continuous low flow [21], meanwhile leading to reduced periphytic algae. As a consequence, the biotic capacity of fish species decreases due to the reduction of abundant and varied food for fish. High flow pulses are vital for reducing any negative effects caused by low flows. Unfortunately, both the number and duration of high pulses reduce in the Jinghe Basin (Table 2), leading to failure in delivering a sufficient nourishing subsidy. The changes of IHAs (decreased magnitude of flow, increased number of low pulses, decreased number and duration of high pulses) described above explain the decrease in the biological integrity of fish to some degree. As suggested by $O D_{-} S D_{m}$, most of the indicators related to the health of the fish community suggest a moderate and high alteration level (Tables 3 and 4), which is an important reason for the poor biological integrity of fish.

On the other hand, the index of water and habitat quality (IWHQ) was used to evaluate the environmental quality in the Wei River Basin, and results show that 7 of 13 sites in the Jinghe Basin were in highly degraded condition (IWHQ > 4) [36]. As the largest tributary of the Wei River Basin, 
this Jinghe Basin suffers poor water and habitat quality. The Jinghe Basin is characterized by high Cond, suspended solids (SS), total phosphorus (TP) and total dissolved solids (TDS).

Table 4. The hydrologic parameters and corresponding changes related to fish integrity.

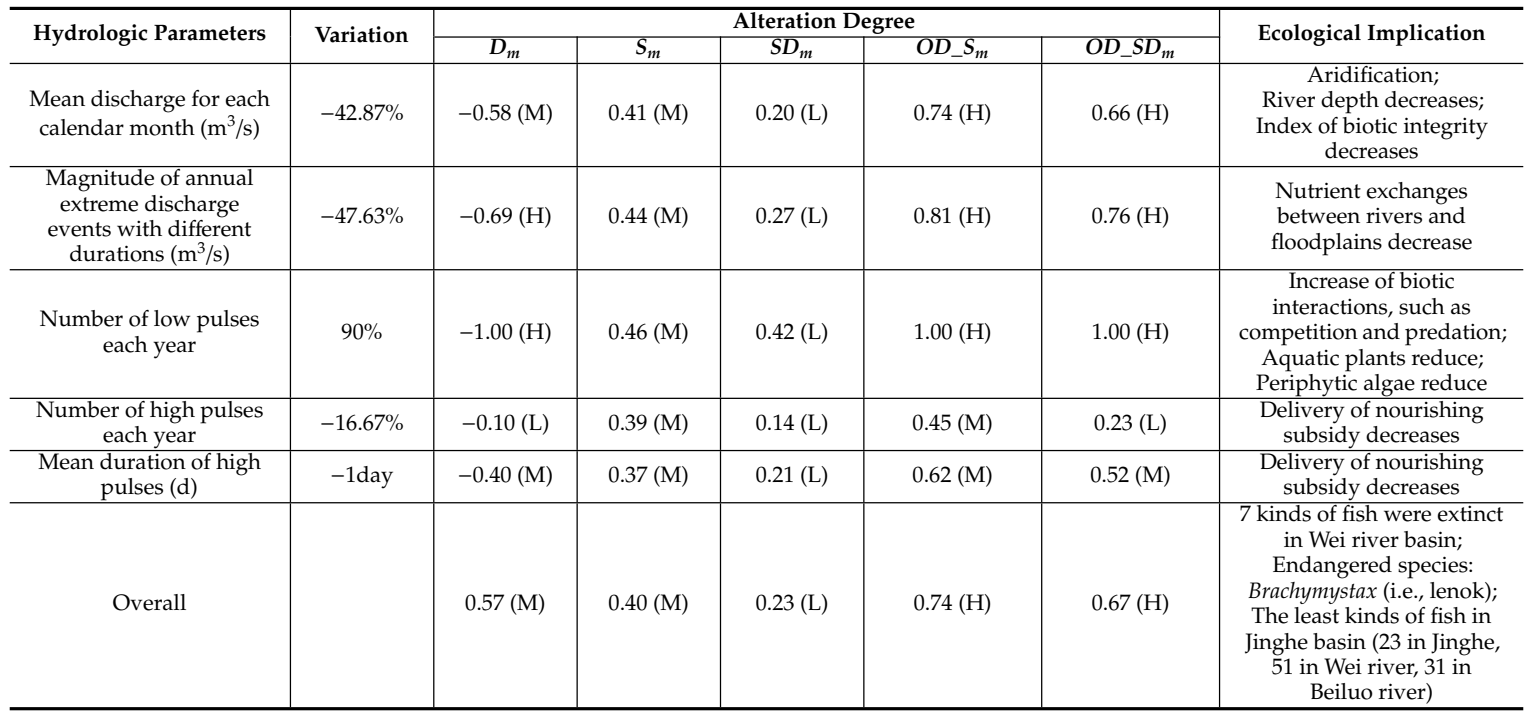

It was mainly caused by three factors [36]: (1) flowing through the Loess Plateau, which exhibits serious soil erosion and high suspended solid, (2) poor water quality in the natural state and characteristics of high total dissolved solids, saline and hardness and (3) a massive development of the petroleum industry in the Malian River that is a tributary of the Jinghe River. The results show that the IBI scores were correlated with IWHQ.

According to the analysis above, it can be concluded that both the alteration of flow regime and the water and habitat quality influence the biotic integrity for fish. It should be noted that the alteration of flow regime is also one of the important factors influencing the water and habitat quality [52]. The soil and water conservation practices, including engineering structures such as terraces and check dams, and biological measures such as afforestation and planting grass, directly alter the flow regime of Jinghe Basin, leading to changes in water and habitat quality. On the other hand, the poor biological integrity of fish also demonstrates the reasonability of the high-level overall alteration suggested by the composite metrics to some degree.

\section{Conclusions}

The natural flow regime is the dominant factor that affects the health of a riverine ecosystem. Climate change and anthropogenic disturbance lead to alteration of the flow regime, commonly causing a series of ecological degradations of rivers. Measuring the extent of the alteration of the flow regime is significant for river protection and restoration. In this study, two new methods were developed for an assessment on flow regime alteration under climate change and human disturbance. The updated methods were employed to detect the flow regime alteration in a typical basin (Jinghe Basin) in the middle reaches of the Yellow River Basin, China. In addition, the alteration levels by three individual metrics and two composite metrics were compared, which were interpreted in terms of the concepts of these metrics. The main points can be summarized as follows:

(1) The concept of similarity/diversity was introduced to formulate the assessment method for flow regime alteration. Two metrics, $S D$ and $S$, were constructed based on the dynamic time warping (DTW) distance and Euclidean distance, respectively. The metrics concentrate on describing the deviation from the prospective of process behaviors in the time series for IHAs, which are supplements of the RVA method that describes the frequency changes of these IHAs. 
(2) The metrics, $S D$ and $S$, were incorporated with the $D$ metric of RVA, respectively. Thereafter, two composite metrics $\left(O D \_S D\right.$ and $\left.O D \_S\right)$ were constructed to comprehensively evaluate the alteration of the flow regime. The composite metrics represent not only the changes in the frequency deviated from the target range, but also the process changes deviated from the pre-impact process. Those composite metrics consistently reveal that the Jinghe Basin suffers a high-level alteration of flow regime, while the conventional RVA method evaluate it as moderate-level. The mean value of all the 12 monthly discharge decreases by $42.87 \%$, the mean value of all the 10 annual extreme discharge decreases by $47.63 \%$ and the number of low pulses each year increase by $90 \%$ (Figure 4), which may be strong evidence for the high-level alteration of flow regime. The composite metrics are recommended rather than RVA for assessment on flow regime alteration due to the complex changes of flow regime under climate change and human activities.

(3) $S D$ suggests a low degree of overall alteration, while $S$ suggests a moderate degree. $S D$ is theoretically more advanced as the time series inputs of the pre-impact and post-impact do not need to be of equal length. Hence, the $S D$ metric based on dynamic time warping (DTW) distance is recommended for assessment on process changes in the time series of IHAs. The OD_SD is more recommended than $O D \_S$.

(4) The high-level changes of IHAs (Table 4) (decreased magnitude of flow, increased number of low pulses) explain the decrease in the biological integrity of fish to some degree. The magnitude of monthly flow and extreme flow decreases ( $42.87 \%$ and $47.63 \%$, respectively), leading to lower river depth and decreased nutrient exchanges between rivers and floodplains. The number of low pulses each year increases obviously (90\%), leading to increased biotic interaction, such as competition and predation.

In a word, high-level alteration of flow regimes leads to decreased biological integrity of fish in the Jinghe Basin, and meanwhile the poor biological integrity of fish to some degree demonstrates the reasonability of the high-level overall alteration suggested by composite measures.

The methods developed in this work can be widely used in other basins with diverse scales worldwide, which enable more scientific evaluation for the complex hydrologic alteration under climate change and anthropogenic disturbance. The achievement of this study facilitates sustainable water resources management and eco-environmental management.

Author Contributions: conceptualization, P.S., T.Y. and Z.L.; methodology, P.S., J.L. and B.Y.; software, P.S., J.L. and Z.L.; validation, T.Y., C.-Y.X.; formal analysis, J.L., S.L. and Z.L.; investigation, T.C., S.L.; resources, T.Y.; data curation, J.L. and Z.L.; writing—original draft preparation, P.S., J.F.; writing-review and editing, P.S., C.-Y.X., J.F.; visualization, T.C.; supervision, T.Y. and C.-Y.X.; project administration P.S.; funding acquisition, P.S. and T.Y.

Funding: This research was funded by a grant from the National Natural Science Foundation of China (51809072), a grant from the Open Research Fund of State Key Laboratory of Simulation and Regulation of Water Cycle in River Basin, China Institute of Water Resources and Hydropower Research(IWHR-SKL-201711), a grant from the Fundamental Research Funds for the Central Universities (2019B16914), a grant from the National Natural Science Foundation of China (51879068), a grant from Key R\&D Program of Ningxia (20175046802), and a grant from National Key R\&D Program of China (2018YFC0407900).

Acknowledgments: Authors are thankful to Hohai University and the China Institute of Water Resources and Hydropower Research for giving space and funding to carry out the research work. All the authors are highly thankful to the reviewers for their fruitful comments to improve the quality of the paper.

Conflicts of Interest: The authors declare no conflict of interest. The funders had no role in the design of the study, nor in the collection, analyses, or interpretation of data, and not in the writing of the manuscript, nor in the decision to publish the results. 


\section{Appendix A}

Table A1. Some terminology and the description.

\begin{tabular}{c|l}
\hline Terminology & \multicolumn{1}{c}{ Description } \\
\hline Discharge & $\begin{array}{l}\text { In hydrology, discharge is the volumetric flow rate of water that is transported through a } \\
\text { given cross-sectional area. }\end{array}$ \\
\hline Biological integrity & $\begin{array}{l}\text { Streamflow, or channel runoff, is the flow of water in streams, rivers, and other channels, } \\
\text { and is a major element of the water cycle. }\end{array}$ \\
\hline Base-flow & $\begin{array}{l}\text { Biological integrity is associated with how "pristine" an environment is, and its function } \\
\text { relative to the potential or original state of an ecosystem before human alterations were } \\
\text { imposed. } \\
\text { Biological integrity is built on the assumption that a decline in the values of an ecosystem's } \\
\text { functions are primarily caused by human activity or alterations. The more an environment } \\
\text { and its original processes are altered, the less biological integrity it holds for the community } \\
\text { as a whole. }\end{array}$ \\
\hline Extreme flow & $\begin{array}{l}\text { Base-flow is the portion of the streamflow that is sustained between precipitation events, } \\
\text { fed to streams by delayed pathways. }\end{array}$ \\
\hline Julian data of annual 1-day minimum/maximum & $\begin{array}{l}\text { It is usually descripted as annual extreme discharge events with different durations, such as } \\
\text { annual 1-,3-,7-,30-,90-day minimum flow, annual 1-,3-,7-,30-,90-day maximum flow. }\end{array}$ \\
\hline Low pulse & $\begin{array}{l}\text { It is a terminology used in indicators of hydrologic alteration (IHAs). If there are multiple } \\
\text { a low pulse if it is less than a specified threshold, which can be set by the user. }\end{array}$ \\
\hline High pulse & $\begin{array}{l}\text { It is a terminology used in indicators of hydrologic alteration (IHAs). A day is classified as } \\
\text { a high pulse if it is greater than a specified threshold, which can be set by the user. }\end{array}$ \\
\hline
\end{tabular}

\section{References}

1. Poff, N.L.; Allan, J.D.; Bain, M.B.; Karr, J.R.; Prestegaard, K.L.; Richter, B.D.; Sparks, R.E.; Stromberg, J.C. The Natural Flow Regime. BioScience 1997, 47, 769-784. [CrossRef]

2. Wang, Y.; Rhoads, B.L.; Wang, D. Assessment of the flow regime alterations in the middle reach of the Yangtze River associated with dam construction: Potential ecological implications. Hydrol. Process. 2016, 30, 3949-3966. [CrossRef]

3. Wang, Y.; Zhang, N.; Wang, D.; Wu, J.; Zhang, X. Investigating the impacts of cascade hydropower development on the natural flow regime in the Yangtze River, China. Sci. Total Environ. 2018, 624, 1187-1194. [CrossRef] [PubMed]

4. Bunn, S.E.; Arthington, A.H. Basic Principles and Ecological Consequences of Altered Flow Regimes for Aquatic Biodiversity. Environ. Manag. 2002, 30, 492-507. [CrossRef]

5. Poff, N.L.; Zimmerman, J.K.H. Ecological responses to altered flow regimes: A literature review to inform the science and management of environmental flows. Freshw. Biol. 2010, 55, 194-205. [CrossRef]

6. Wang, X.; Yang, T.; Wortmann, M.; Shi, P.; Hattermann, F.; Lobanova, A.; Aich, V. Analysis of multi-dimensional hydrological alterations under climate change for four major river basins in different climate zones. Clim. Chang. 2017, 141, 483-498. [CrossRef]

7. Zhang, Q.; Zhang, Z.; Shi, P.; Singh, V.P.; Gu, X. Evaluation of ecological instream flow considering hydrological alterations in the Yellow River basin, China. Glob. Planet. Chang. 2018, 160, 61-74. [CrossRef]

8. Huang, C.-S.; Yang, T.; Yeh, H.-D. Review of analytical models to stream depletion induced by pumping: Guide to model selection. J. Hydrol. 2018, 561, 277-285. [CrossRef]

9. Qin, Y.; Kavetski, D.; Kuczera, G. A Robust Gauss-Newton Algorithm for the Optimization of Hydrological Models: From Standard Gauss-Newton to Robust Gauss-Newton. Water Resour. Res. 2018, 54, 9655-9683. [CrossRef]

10. Yang, T.; Cui, T.; Xu, C.-Y.; Ciais, P.; Shi, P. Development of a new IHA method for impact assessment of climate change on flow regime. Glob. Planet. Chang. 2017, 156, 68-79. [CrossRef]

11. Shi, P.; Yang, T.; Xu, C.-Y.; Yong, B.; Shao, Q.; Li, Z.; Wang, X.; Zhou, X.; Li, S. How do the multiple large-scale climate oscillations trigger extreme precipitation? Glob. Planet. Chang. 2017, 157, 48-58. [CrossRef]

12. Xu, X.; Allah, A.E.; Wang, C.; Tan, H.; Farghali, A.A.; Khedr, M.H.; Malgras, V.; Yang, T.; Yamauchi, Y. Capacitive deionization using nitrogen-doped mesostructured carbons for highly efficient brackish water desalination. Chem. Eng. J. 2019, 362, 887-896. [CrossRef]

13. Xu, X.; Tan, H.; Wang, Z.; Wang, C.; Pan, L.; Kaneti, Y.V.; Yang, T.; Yamauchi, Y. Extraordinary capacitive deionization performance of highly-ordered mesoporous carbon nano-polyhedra for brackish water desalination. Environ. Sci. Nano 2019, 6, 981-989. [CrossRef] 
14. Poff, N.L.; Allan, J.D. Functional Organization of Stream Fish Assemblages in Relation to Hydrological Variability. Ecology 1995, 76, 606-627. [CrossRef]

15. Clausen, B.; Biggs, B.J.F. Flow variables for ecological studies in temperate streams: Groupings based on covariance. J. Hydrol. 2000, 237, 184-197. [CrossRef]

16. Pettit, N.E.; Froend, R.H.; Davies, P.M. Identifying the natural flow regime and the relationship with riparian vegetation for two contrasting western Australian rivers. Regul. Rivers Res. Manag. 2001, 17, 201-215. [CrossRef]

17. Magilligan, F.J.; Nislow, K.H. Changes in hydrologic regime by dams. Geomorphology 2005, 71, 61-78. [CrossRef]

18. Richter, B.D.; Baumgartner, J.V.; Powell, J.; Braun, D.P. A Method for Assessing Hydrologic Alteration within Ecosystems. Conserv. Biol. 1996, 10, 1163-1174. [CrossRef]

19. Olden, J.D.; Poff, N.L. Redundancy and the choice of hydrologic indices for characterizing streamflow regimes. River Res. Appl. 2003, 19, 101-121. [CrossRef]

20. Richter, B.; Baumgartner, J.; Wigington, R.; Braun, D. How much water does a river need? Freshw. Biol. 1997, 37, 231-249. [CrossRef]

21. Cui, T.; Yang, T.; Xu, C.-Y.; Shao, Q.; Wang, X.; Li, Z. Assessment of the impact of climate change on flow regime at multiple temporal scales and potential ecological implications in an alpine river. Stoch. Environ. Res. Risk Assess. 2018, 32, 1849-1866. [CrossRef]

22. Yin, X.A.; Yang, Z.F.; Petts, G.E. A New Method to Assess the Flow Regime Alterations in Riverine Ecosystems. River Res. Appl. 2015, 31, 497-504. [CrossRef]

23. Todeschini, R.; Ballabio, D.; Consonni, V.; Mauri, A. A new similarity/diversity measure for sequential data. Match Commun. Math. Comput. Chem. 2007, 57, 51-67.

24. $\mathrm{Xu}, \mathrm{J}$. River sedimentation and channel adjustment of the lower Yellow River as influenced by low discharges and seasonal channel dry-ups. Geomorphology 2002, 43, 151-164. [CrossRef]

25. Gao, P.; Mu, X.M.; Wang, F.; Li, R. Changes in streamflow and sediment discharge and the response to human activities in the middle reaches of the Yellow River. Hydrol. Earth Syst. Sci. 2011, 15, 1-10. [CrossRef]

26. Fu, G.; Charles, S.P.; Viney, N.R.; Chen, S.; Wu, J.Q. Impacts of climate variability on stream-flow in the Yellow River. Hydrol. Process. 2007, 21, 3431-3439. [CrossRef]

27. Li, L.-J.; Zhang, L.; Wang, H.; Wang, J.; Yang, J.-W.; Jiang, D.-J.; Li, J.-Y.; Qin, D.-Y. Assessing the impact of climate variability and human activities on streamflow from the Wuding River basin in China. Hydrol. Process. 2007, 21, 3485-3491. [CrossRef]

28. Yang, T.; Zhang, Q.; Chen, Y.D.; Tao, X.; Xu, C.-Y.; Chen, X. A spatial assessment of hydrologic alteration caused by dam construction in the middle and lower Yellow River, China. Hydrol. Process. 2008, 22, 3829-3843. [CrossRef]

29. Liu, J.; Zhang, Q.; Singh, V.P.; Shi, P. Contribution of multiple climatic variables and human activities to streamflow changes across China. J. Hydrol. 2017, 545, 145-162. [CrossRef]

30. Zhao, G.; Mu, X.; Wen, Z.; Wang, F.; Gao, P. Soil erosion, conservation, and eco-environment changes in the loess plateau of China. Land Degrad. Dev. 2013, 24, 499-510. [CrossRef]

31. Zhao, G.; Tian, P.; Mu, X.; Jiao, J.; Wang, F.; Gao, P. Quantifying the impact of climate variability and human activities on streamflow in the middle reaches of the Yellow River basin, China. J. Hydrol. 2014, 519, 387-398. [CrossRef]

32. Ren, W.; Yang, T.; Shi, P.; Xu, C.-Y.; Zhang, K.; Zhou, X.; Shao, Q.; Ciais, P. A probabilistic method for streamflow projection and associated uncertainty analysis in a data sparse alpine region. Glob. Planet. Chang. 2018, 165, 100-113. [CrossRef]

33. Kumar, A.; Yang, T.; Sharma, M.P. Long-term prediction of greenhouse gas risk to the Chinese hydropower reservoirs. Sci. Total Environ. 2019, 646, 300-308. [CrossRef] [PubMed]

34. Wang, X.; Yang, T.; Yong, B.; Krysanova, V.; Shi, P.; Li, Z.; Zhou, X. Impacts of climate change on flow regime and sequential threats to riverine ecosystem in the source region of the Yellow River. Environ. Earth Sci. 2018, 77, 465. [CrossRef]

35. Wu, W.; Xu, Z.; Zhan, C.; Yin, X.; Yu, S. A new framework to evaluate ecosystem health: A case study in the Wei River basin, China. Environ. Monit. Assess. 2015, 187, 460. [CrossRef]

36. Wu, W.; Xu, Z.; Yin, X.; Zuo, D. Assessment of ecosystem health based on fish assemblages in the Wei River basin, China. Environ. Monit. Assess. 2014, 186, 3701-3716. [CrossRef] 
37. Wu, W.; Xu, Z.; Kennard, M.J.; Yin, X.; Zuo, D. Do human disturbance variables influence more on fish community structure and function than natural variables in the Wei River basin, China? Ecol. Indic. 2016, 61, 438-446. [CrossRef]

38. Moraes, J.M.; Pellegrino, G.Q.; Ballester, M.V.; Martinelli, L.A.; Victoria, R.L.; Krusche, A.V. Trends in Hydrological Parameters of a Southern Brazilian Watershed and its Relation to Human Induced Changes. Water Resour. Manag. 1998, 12, 295-311. [CrossRef]

39. Pettitt, A.N. A Non-Parametric Approach to the Change-Point Problem. J. R. Stat. Soc. Ser. C 1979, 28, 126-135. [CrossRef]

40. Mann, H.B. Nonparametric Tests Against Trend. Econometrica 1945, 13, 245-259. [CrossRef]

41. Lin, K.; Lin, Y.; Xu, Y.; Chen, X.; Chen, L.; Singh, V.P. Inter- and intra- annual environmental flow alteration and its implication in the Pearl River Delta, South China. J. Hydro-Environ. Res. 2017, 15, 27-40. [CrossRef]

42. Friedrich-Wilhelm, G.; Peter, C.W. Estimation of the beginning and end of recurrent events within a climate regime. Clim. Res. 1999, 11, 97-107. [CrossRef]

43. Karabörk, M.Ç. Trends in drought patterns of Turkey. J. Environ. Eng. Sci. 2007, 6, 45-52. [CrossRef]

44. Richter, B.D.; Baumgartner, J.V.; Braun, D.P.; Powell, J. A spatial assessment of hydrologic alteration within a river network. Regul. Rivers Res. Manag. 1998, 14, 329-340. [CrossRef]

45. Kruskal, J.B.; Liberman, M. Time Warps, String Edits, and Macromolecules: The Theory and Practice of Sequence Comparison; Cambridge University Press: Cambridge, MA, USA, 1983.

46. Berndt, D.J.; Clifford, J. Using dynamic time warping to find patterns in time series. In Proceedings of the 3rd International Conference on Knowledge Discovery and Data Mining, Seattle, WA, USA, 14-17 August 1997; pp. 359-370.

47. Keogh, E.J.; Pazzani, M.J. Scaling up dynamic time warping for datamining applications. In Proceedings of the Sixth ACM SIGKDD International Conference on Knowledge Discovery and Data Mining, Boston, MA, USA, 20-23 August 2000; pp. 285-289.

48. Ouyang, R.; Ren, L.; Cheng, W.; Zhou, C. Similarity search and pattern discovery in hydrological time series data mining. Hydrol. Process. 2010, 24, 1198-1210. [CrossRef]

49. Salvador, S.; Chan, P. Toward accurate dynamic time warping in linear time and space. Intell. Data Anal. 2007, 11, 561-580. [CrossRef]

50. Stanford, J.A.; Ward, J.V.; Liss, W.J.; Frissell, C.A.; Williams, R.N.; Lichatowich, J.A.; Coutant, C.C. A General Protocol for Restoration of Regulated Rivers. Regul. Rivers Res. Manag. 1996, 12, 391-413. [CrossRef]

51. Magoulick, D.D.; Kobza, R.M. The role of refugia for fishes during drought: A review and synthesis. Freshw. Biol. 2003, 48, 1186-1198. [CrossRef]

52. Li, Z.; Yang, T.; Huang, C.-S.; Xu, C.-Y.; Shao, Q.; Shi, P.; Wang, X.; Cui, T. An improved approach for water quality evaluation: TOPSIS-based informative weighting and ranking (TIWR) approach. Ecol. Indic. 2018, 89, 356-364. [CrossRef]

(C) 2019 by the authors. Licensee MDPI, Basel, Switzerland. This article is an open access article distributed under the terms and conditions of the Creative Commons Attribution (CC BY) license (http://creativecommons.org/licenses/by/4.0/). 